\title{
In Vitro and In Vivo Effects of Metformin on Osteopontin Expression in Mice Adipose-Derived Multipotent Stromal Cells and Adipose Tissue
}

\author{
Agnieszka Śmieszek, ${ }^{1,2}$ Katarzyna Basińska, ${ }^{1}$ Klaudia Chrząstek, ${ }^{1}$ and Krzysztof Marycz ${ }^{1,2}$ \\ ${ }^{1}$ The Faculty of Biology and Animal Science, University of Environmental and Life Sciences, Kozuchowska 5b Street, \\ 50-631 Wroclaw, Poland \\ ${ }^{2}$ Wrocławskie Centrum Badań EIT+, Stablowicka 147 Street, 54-066 Wroclaw, Poland
}

Correspondence should be addressed to Krzysztof Marycz; krzysztofmarycz@interia.pl

Received 20 January 2015; Revised 2 April 2015; Accepted 9 April 2015

Academic Editor: Daisuke Koya

Copyright ( 2015 Agnieszka Śmieszek et al. This is an open access article distributed under the Creative Commons Attribution License, which permits unrestricted use, distribution, and reproduction in any medium, provided the original work is properly cited.

\begin{abstract}
Metformin is applied not only as antidiabetic drug, but also in the treatment of obesity or as antiaging drug. The first part of the research discussed the effect of metformin at concentrations of $1 \mathrm{mM}, 5 \mathrm{mM}$, and $10 \mathrm{mM}$ on the morphology, ultrastructure, and proliferation potential of mice adipose-derived multipotent mesenchymal stromal cells (ASCs) in vitro. Additionally, we determined the influence of metformin on mice adipose tissue metabolism. This study has shown for the first time that metformin inhibits the proliferative potential of ASCs in vitro in a dose- and time-dependent manner. In addition, we have found a significant correlation between the activity of ASCs and osteopontin at the mRNA and protein level. Furthermore, we have demonstrated that $5 \mathrm{mM}$ and $10 \mathrm{mM}$ metformin have cytotoxic effect on ASCs, causing severe morphological, ultrastructural, and apoptotic changes. The reduced level of OPN in the adipose tissue of metformin-treated animals strongly correlated with the lower expression of Ki67 and CD105 and increased caspase-3. The metformin influenced also circulating levels of OPN, which is what was found with systemic and local action of metformin. The results are a valuable source of information regarding the in vitro effect of metformin on adipose-derived stem cells.
\end{abstract}

\section{Introduction}

Metformin ( $\mathrm{N}, \mathrm{N}^{\prime}$-dimethylbiguanide) is a widely used drug for the treatment of type 2 diabetes mellitus, condition associated with insulin sensitivity and obesity. Additionally, it has been shown that metformin may inhibit growth of tumor cells and thus potentially may find application in therapy of various types of cancer [1-6]. Metformin was also classified for conceptual group of drugs, known as calorie restriction mimetics (CRM). Anisimov et al. [7] have shown that calorie restriction model involving metformin supplementation is a very effective way of increasing the lifespan by reducing morbidity and mortality both of healthy mice and of mice with tumor.

The progressive aging of the human population together with increasing obesity are the main reasons of metabolic diseases [8]. The World Health Organization (WHO) reported that over 500 million people suffer from overweight and/or obesity (data from 2013). This serious medical condition becomes a great challenge for modern pharmacotherapy. Metformin is considered a part of the solution to this problem due to its multidirectional action on adipose tissue metabolism $[9,10]$. Metformin has an ability to decrease adiposity and obesity related conditions what was proved either in human or animal model [11-14]. Additionally, according to a randomized study performed by Srinivasan et al. [13] and Yanovski et al. [14] children and adolescents may be much more responsive to metformin-induced weight reduction as compared to adults. These results might suggest that the metformin has an effect not only on morphology and distribution of fat tissue but also on proliferation potential of adipocytes precursors. 
Progenitor cells in the uncultured stroma-vascular fraction (SVF) derived from adipose tissue usually amount to up to $3 \%$ of the whole cells. This unique population is defined as adipose-derived multipotent stromal cells, ASCs $[15,16]$. Although ASCs are of mesoderm origin, these stem cells possess a unique ability to differentiate into ectoderm and endoderm lineages as well as mesoderm cells [17]. ASCs are increasingly being not only used as a research tool, but also applied in the human and veterinary medicine cell therapy. The reason for this is that they can be easily obtained in large quantities with little donor site morbidity or patient discomfort. ASCs become a source of cells characterized by high proliferative potential, stable growth, and kinetics and thus are considered a promising candidate in regenerative medicine. ASC-based therapies have been shown to be safe and efficacious in the preclinical and clinical studies of various injuries and diseases $[18,19]$.

Given the fact that metformin exerts an unquestionable influence on adipose tissue, which becomes a source of a unique stem cell population, it was reasonable to investigate the effects of this compound on the proliferation potential, morphology, and ultrastructure of the ASCs.

Markers that can be associated with cells proliferation are Ki-67 and osteopontin (OPN). Additionally, expression of another marker, for example, CD105/endoglin, should be taken into consideration, because it defines MSCs provenance and is associated with preadipocytes proliferation and differentiation potential $[20,21]$. Ki-67 is a ubiquitous human nuclear protein expressed in $G_{1}, S$, and $G_{2}$ phases of the cell cycle $[22,23]$ and therefore is used as indicator of growth fraction of particular cells population. Ki-67 was also used to quantify preadipocyte replication when assessing cellular turnover within adipose tissue of mice and humans [24]. In turn, osteopontin is a multifunctional protein mainly associated with osseous tissue metabolism and bone remodeling [25]. It is expressed in proliferating fibroblast and in osteogenic and periodontal ligament cell populations $[26,27]$. Moreover, OPN upregulation is also connected with variety of acute and chronic inflammatory conditions, such as wound healing, fibrosis, autoimmune disease, and atherosclerosis [28]. The osteopontin is also regarded as a mediator linking obesity to the development of insulin resistance by promoting inflammation and the accumulation of macrophages in adipose tissue [29].

Bearing in mind all mentioned facts, determination of expressions of $\mathrm{Ki}-67$ and osteopontin in adipose tissue of mice treated with metformin seems to be crucial regarding its influence on ASCs proliferation activity. To the best of our knowledge, this issue has never been investigated previously. Therefore, to obtain complex information concerning effect of metformin of ASCs and adipose tissue, we decided to approach this subject bidirectionally, performing in vitro and in vivo studies. Analysis of cytotoxic effect of metformin was performed on ASCs isolated from mice. We evaluated not only proliferative activity of ASCs exposed to metformin, but also their morphology and ultrastructure. Additionally we investigated the OPN gene expression and protein secretion.

Metformin accumulates in tissues of diabetic mice in concentrations several times higher than those in blood $[30,31]$, and therefore three concentrations of metformin $(1 \mathrm{mM}$, $5 \mathrm{mM}$, and $10 \mathrm{mM}$ ) were applied in this study.

The aim of in vivo study was to evaluate the effect of metformin on histological structure of adipose tissue and to determine expression of proliferation markers. We believed that the data presented in this study will provide meaningful information of clinical significance, especially due to the fact that substantial part of our research was dedicated to cells morphology investigation, important in diagnosis of pathology.

\section{Material and Methods}

All reagents used in this experiment were purchased from Sigma-Aldrich (Poland), unless indicated otherwise.

All experimental procedures were approved by the II Local Ethics Committee of Environmental and Life Science University (Dec. No. 177/2010 of 11.15.2010).

\subsection{In Vitro Study}

2.1.1. Isolation of Mesenchymal Stromal Cells from Adipose Tissue. The cells were isolated from subcutaneous adipose tissue of six C57BL/6 mice using protocol established previously $[32,33]$. Material was collected from the abdominal region of each animal. Tissue fragments were minced and digested using type I collagenase for 40 minutes at $37^{\circ} \mathrm{C}$. Next, the tissue homogenates were centrifuged for $10 \mathrm{~min}$ at $1200 \times \mathrm{g}$. The supernatants were aspirated and the pellets of the stromal-vascular adipose fraction, containing MSCs precursors, were washed with Hank's balanced salt solution and centrifuged three times $(5 \mathrm{~min}$ at $600 \times \mathrm{g})$. Pellets were then suspended in Dulbecco's modified Eagle's medium (DMEM) with Nutrient F-12 Ham and transferred to culture flasks. Cultures were maintained at $37^{\circ} \mathrm{C}$ in a humidified atmosphere of $5 \% \mathrm{CO}_{2}$ and $95 \%$ air. The cells were passaged after reaching $80-90 \%$ confluence. Subsequent cultures were propagated in DMEM containing $4500 \mathrm{mg} / \mathrm{L}$ of glucose. Culture media were supplemented with 10\% FBS and 1\% antibiotics (penicillin and streptomycin). The medium was changed every two days. Before experiment, the cells were passaged three times, using trypsin solution (TrypLE; Life Technologies) according to manufacturers' instruction.

2.1.2. Phenotypic Characterization of Isolated Cells and Multipotency Assay. Phenotypic characterization of cells was performed using ASCs cultures derived from animals assigned for in vitro tests. Analyzed cells were adjusted in terms of subculture (all after second passage). For staining, cultures were maintained in 24-well dishes designated for immunofluorescence preparations (Sarstedt). For each staining, cultures were run in triplicate. To determine the phenotype of cells, the expression of following markers was investigated: CD29, CD44, CD45, CD73, and CD105. The antibodies used for the analysis were purchased from Sigma (rabbit anti-mouse integrin-b-1 (CD29), dilution 1:100; rabbit anti-mouse NT5E (CD73), dilution 1:200; rabbit anti-mouse endoglin (CD105), dilution 1:200; rabbit anti-mouse CD45, dilution 1:100), 
except for anti-CD44 which was obtained from R\&D Systems (rabbit anti-mouse CD44, dilution 1:100). Secondary antibody conjugated with atto- 488 fluorescence label was purchased from Sigma (goat anti-mouse IgG atto-488, dilution $1: 400)$. Immunocytochemistry was performed using the general protocol described by the manufacturer. Incubation with primary antibodies was carried out overnight, while the reaction with secondary antibodies was performed at $37^{\circ} \mathrm{C}$ for 1 hour in the dark. In order to determine background fluorescence and exclude nonspecific staining, negative controls were included to assess the binding specificity of secondary antibodies. Negative controls were incubated with secondary antibody for 1 hour at $37^{\circ} \mathrm{C}$ in the dark. Additionally, specimens were counterstained with $4^{\prime}, 6$-diamidino-2phenylindole (DAPI) to visualize the nuclei. The samples were imaged using an inverted fluorescence microscope (AxioObserverA1, Carl Zeiss, Jena, Germany). Images were captured with Cannon PowerShot camera and merged using AxioVision 4.8 software (Carl Zeiss, Jena, Germany).

\subsubsection{Determination of Multipotent Character of Mice ASCs.} Osteogenic and adipogenic differentiation of ASCs were induced using commercial kits (StemPro, Life Technologies). Cultures under standard and osteo- and adipogenic conditions were maintained in 24-well dishes. Experiments were carried out simultaneously, each in triplicate according to the previous findings [33]. Osteogenesis was induced during 21day period, while stimulation toward adipocytes lasted for 14 days. To evaluate results of osteogenic and adipogenic differentiation, two specific staining methods were used, that is, Alizarin Red for determination of calcium deposits and detection of neutral lipid deposits performed using HCS LipidTOX Green neutral lipid stain, and according to the manufacturers' instruction preparations were analyzed using Axio Observer A1 inverted and epifluorescent microscope (Axio Observer A1, Carl Zeiss, Jena, Germany), while the documentation was made using Cannon PowerShot camera.

\subsubsection{ASC Proliferation Assay. For assays, cells were seeded} in 24-well plates at a concentration equal to $3 \times 10^{4}$. Cells were suspended in $0.5 \mathrm{~mL}$ of culture medium per well. Metformin hydrochloride (Metformax 850, Teva Pharmaceuticals, Poland) was crushed in a mortar and dissolved in the culture medium at the following concentrations: $1 \mathrm{mM}$, $5 \mathrm{mM}$, and $10 \mathrm{mM}$. Nontreated cells served as a control for comparison with the test culture. In order to performe further analysis (including morphology, ultrastructure, and gene expression), each culture was performed in six replications. Proper number of culture plates was performed to investigate cells in the chosen time-points. The first dosage of metformin was added to the culture after 24 hours. During the cell treatment medium was changed every day. Culture media were collected for determination of protein level. The viability of the cells was evaluated after 24,48 , and 72 hours using a resazurin-resorufin system (Alamar Blue). To perform the test, culture media were removed and replaced with a medium containing $10 \%$ of the dye. Cells were incubated with the dye in the $\mathrm{CO}_{2}$ incubator for 2 hours. The supernatants were collected and transferred to a 96-well microplate reader (Spectrostar Nano, BMG Labtech). The absorbance of the supernatants was measured spectrophotometrically at a wavelength of $600 \mathrm{~nm}$ for resazurin and $690 \mathrm{~nm}$ as a reference wavelength. Each measurement included a blank sample, containing complete medium without cells. Proliferation activity was described using $\Delta \Delta A$ value, expressing difference of absorbance of supernatants at 600 and $690 \mathrm{~nm}$ and including absorbance of blank samples.

\subsubsection{Examination of Morphology, Viability, and Ultrastruc-} ture of ASCs. ASC morphology was evaluated under epifluorescent microscope (Zeiss, Axio Observer Al) and scanning electron microscope (SEM, Zeiss Evo LS 15). The analysis of morphology was performed after $24 \mathrm{~h}$ and $72 \mathrm{~h}$ of culture in 24-well plates. The preparation of ASCs for fluorescent microscopy was performed according to established procedure $[34,35]$ and included the following stages: (i) washing three times using HBSS, 1 min each; (ii) fixation of cells in $4 \%$ ice cold paraformaldehyde, performed overnight at $4^{\circ} \mathrm{C}$; (iii) washing of cells (as described above); (iv) $15 \mathrm{~min}$ of cell permeabilization with $0.1 \%$ Triton X-100 at room temperature; (v) washing of cells (as described above); (vi) staining with atto-488-labeled phalloidin $(1: 800)$ for $30 \mathrm{~min}$ performed in the dark at room temperature; (vii) counterstaining using diamidino-2-phenylindole (DAPI; 1:1000) for $5 \mathrm{~min}$ at room temperature. For the detection of apoptotic cells, simultaneously to DAPI staining, immunofluorescence staining of caspase-3 was performed using polyclonal rabbit anti-mouse caspase- 3 antibody (dilution $1: 100$ ). Additionally, for detection of dead and apoptotic cells analysis using Cellstain Double Staining Kit with propidium iodide was conducted. Staining procedure was performed according to the protocols available from the manufacturers. Images were captured using Cannon PowerShot Camera.

For SEM analysis, (i) cells were fixed in $2.5 \%$ glutaraldehyde in DMEM, (ii) rinsed with HBSS, (iii) dehydrated in a graded ethanol series (from $50 \%$ to $100 \%$, increasing every $10 \%)$, (iv) air-dried for $30 \mathrm{~min}$ at room temperature, and (v) coated with gold using 300-second program (Edwards, Scancoat six). Prepared samples were captured using a SE1 detector at $10 \mathrm{kV}$ filament tension (SEM, Zeiss Evo LS 15) under 500x and 5000x magnification.

For TEM analysis, we used procedure described previously [36]. Briefly, cells were fixed overnight at $4^{\circ} \mathrm{C}$ in $2.5 \%$ glutaraldehyde in DMEM. After fixation, cells were centrifuged at $2000 \times \mathrm{g}$ for $10 \mathrm{~min}$ and rinsed with PBS $(0.1 \mathrm{M}$, $\mathrm{pH}=7.0$ ) for $30 \mathrm{~min}$ at room temperature. After washing, cells were centrifuged again using parameters provided above. Pellets were incubated with $1 \%$ osmium tetroxide in PBS for 2 hours. Cells were washed once again using 0.1 M PBS and centrifuged. Following this procedure, the cells were dehydrated in a graded acetone series (30-100\%) and embedded using Agar Low Viscosity Resin Kit (Agar Scientific Ltd., Stansted). Ultrathin sections $(80 \mathrm{~nm})$ of the specimens were collected on copper grids. Cells were contrasted with uranyl acetate (30 min incubation) and lead citrate (15 min 
incubation). Cells were imaged with TEM detector, at $10 \mathrm{kV}$ filament tension.

2.1.6. Analysis of Gene Expression: Real-Time Reverse Transcription Polymerase Chain Reaction (qRT-PCR). After 24 and 72 hours of culture, cells were rinsed twice using HBSS and then homogenized using $0.8 \mathrm{~mL}$ of TRI Reagent. Procedure of cells' homogenization was performed directly in the culture dish. Preparations were obtained from samples prepared in duplicate. Total RNA was isolated using a singlestep method described by Chomczynski and Sacchi [37]. The resulting samples were diluted in DEPC-treated water. The quantity and quality of total RNA were determined using a nanospectrophotometer (VPA biowave II). Traces of genomic DNA (gDNA) were digested with DNase I RNase-free kit (Thermo Scientific). Each reaction contained $100 \mathrm{ng}$ of total RNA. Complementary DNA (cDNA) was obtained in the reaction with Moloney Murine Leukemia Virus Reverse Transcriptase (M-MLV RT) and oligo(dT)15 primers (Verte KIT oligo(dT)15, Novazym). Both RNA purification and cDNA synthesis were performed in accordance with manufacturers' instructions using the T100 Thermal Cycler (Bio-Rad). Detection of osteopontin was performed using following primers: (i) forward 5 -AGACCATGCAGAGAGCGAG- $3^{\prime}$ and (ii) reverse $5^{\prime}$-GCCCTTTCCGTTGTTGTCCT-3' (NCBI accession number: NM_001204203.1). Beta-2 microglobulin $(\beta 2 \mathrm{M})$ was used as housekeeping gene; sequences of primers were as follows: (i) forward $5^{\prime}$ CATACGCCTGCAGAGTTAAGCA- $3^{\prime}$ and (ii) reverse $5^{\prime}$ GATCACATGTCTCGATCCCAGTAG-3' (NCBI accession number: NM_009735.3). Quantitative RT-PCR was carried out in a total volume of $20 \mu \mathrm{L}$ using SensiFast SYBR and Fluorescein Kit (Bioline). The concentration of primers in each reaction was $500 \mathrm{nM}$. The following cycling conditions were applied: $95^{\circ} \mathrm{C}$ for $2 \mathrm{~min}$, followed by 45 cycles at $95^{\circ} \mathrm{C}$ for $5 \mathrm{sec}$, annealing $58^{\circ} \mathrm{C}$ for $10 \mathrm{sec}$, and $72^{\circ} \mathrm{C}$ step for $5 \mathrm{sec}$ with a single fluorescence measurement. Analysis of the dissociation curve of amplicons was performed to determine the specificity of the PCR products. Melting curve was determined with a gradient program of the range from 65 to $95^{\circ} \mathrm{C}$ at a heating rate of $0.2^{\circ} \mathrm{C} / \mathrm{s}$ and continuous measurement of the fluorescence. Reactions were performed in three repetitions. The values of the threshold cycle $(\mathrm{Ct})$ obtained in each experiment were used to calculate fold change in relation to the expression of housekeeping gene. Real-time PCR was performed using CFX Connect Real-Time PCR Detection System (BioRad).

2.1.7. Osteopontin Detection in Culture Supernatants. The osteopontin level was determined in supernatants collected after experimental cultures. For analysis, each culture medium was prepared in duplicate. The concentration of OPN was measured by enzyme-linked immunosorbent assay (ELISA) using a commercially available ELISA kit (DuoSet ELISA Development kit; R\&D Systems). ELISA was performed according to the manufacturer's instructions. For the analysis, supernatants were diluted 5 times. All tested samples and standards were measured in two replicates.

\subsection{In Vivo Study}

2.2.1. Animals and Subcutaneous Tissue Collection. Eighteen C57BL/6 mice (females, 4-week-old) were housed three per cage in an ultraclean facility on ventilated racks and were provided food and water ad libitum during the 5week experiment. The animals were purchased from Animal Laboratory House, Wroclaw Medical School, and housed in the Animal Experimental Laboratory (Wroclaw Medical School, Poland). Mice received a standard diet with $4,2 \%$ fat (Morawski, Labofeed $\mathrm{H}$, Poland) and were maintained on a 12-hour light-dark cycle at $22 \pm 0.2^{\circ} \mathrm{C}$.

The animals used in the study were divided into two groups: (i) control $(n=9)$ receiving drinking water only and (ii) the group receiving metformin in drinking water at a concentration equal to 2,8 mg/day (Metformax 850; Teva Pharmaceuticals, Poland) $(n=9)$. Water was changed every two days.

After the experiment, mice were fasted for $24 \mathrm{~h}$. Body weight measurement was carried out using electronic weight (RADWAG PS/C1 series, Poland). Blood was collected from animals using cardiac puncture method. Biochemical analysis of blood samples, such as glucose and lipids measurements, was performed with Erba XL 300 platform (Erba Diagnostics Mannheim GmbH, Germany). After euthanasia of animals, adipose tissue was collected from abdominal subcutaneous layer of all animals.

2.2.2. Histology and Immunohistochemistry. Subcutaneous adipose tissue $(0.5 \mathrm{~g})$ was fixed in a cold $4 \%$ paraformaldehyde (Sigma-Aldrich). Next, samples were transferred to $0.1 \mathrm{M}$ phosphate buffer and incubated for 24 hours. The samples were then treated with $18 \%$ sucrose for three days. The samples were applied on a specimen holder using tissue freezing medium and transferred to a freezer $\left(-20^{\circ} \mathrm{C}\right)$. The samples were cut into sections of $0.5 \mu \mathrm{m}$ thickness and subsequently stained using Mayer hematoxylin (Sigma-Aldrich). Sections were prepared in six replicates and deposited on Superfrost Ultra Plus Adhesion Slides (Thermo Scientific).

Morphometric analysis of adipose tissue was performed with Axio Imager light microscope (Zeiss) using 10 fields of view for each individual (each slide) based on our previous experience [38]. Histological photographs were compiled using an Axio Camera (Zeiss).

The Image J software (http://rsbweb.nih.gov/ij/) was used to measure size and area of adipocytes. Adipocytes that were damaged or overly distorted owing to processing were not included in the measurements. Moreover, number of crownlike structures (CLS) was determined from six random microscopic fields magnified 100x.

For immunohistochemistry, $4 \mu \mathrm{m}$ frozen sections were placed on Superfrost Ultra Plus Adhesion Slides (Thermo Scientific). The samples were stored at $-20^{\circ} \mathrm{C}$ and before preparations were rehydrated. For each staining, two specimens were prepared. Antibodies used in the experiment were raised against mouse OPN, Ki67 (1:200) (both purchased from Abcam), and caspase-3 markers (1:100) (Sigma) as well as CD44 (1:500) and CD105 (1:100) antigens (both from Abcam). Obtained samples were incubated with specific 

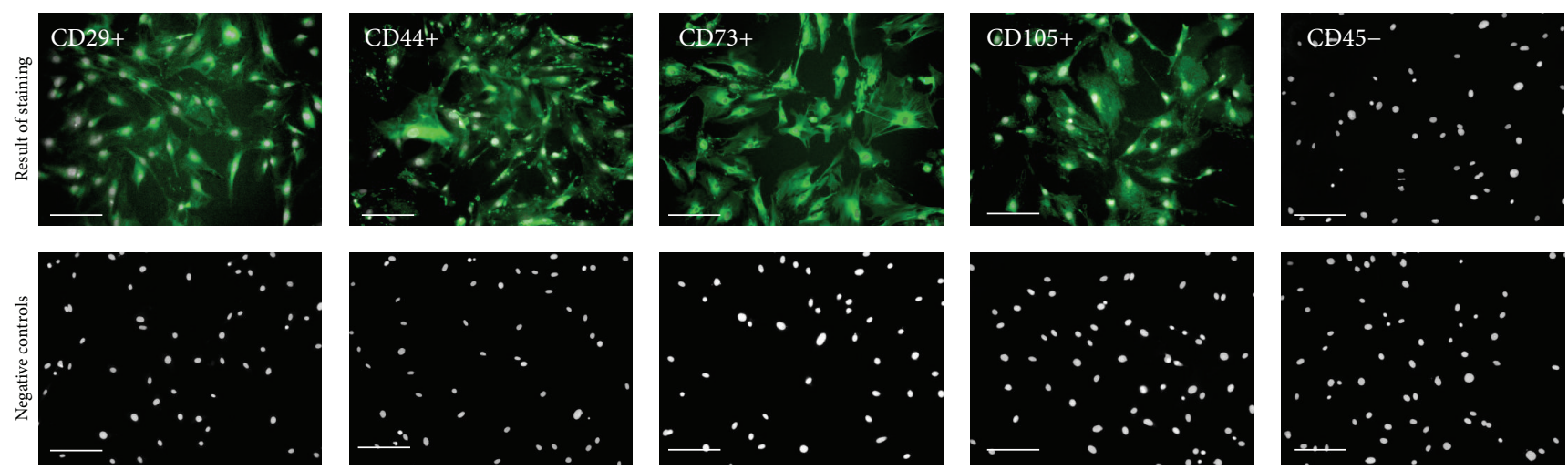

FIGURE 1: The results of mice adipose-derived mesenchymal stem cells immunophenotyping represented in images. Immunostaining analysis was performed on three ASCs cultures, after second passage. The obtained populations of cells were positive for markers characteristic for mesenchymal cells, that is, CD29, CD44, CD73, and CD105, and were negative for hematopoietic marker CD45. Particular markers were stained with specific primary antibody and secondary antibody conjugated with atto- 488 (positive reactions shown in green), and nuclei stained with DAPI are shown in white. Results of negative staining are included in the Figure. Magnification used is $100 x$. Scale bar $=250 \mu \mathrm{m}$.

antibodies over night at $4^{\circ} \mathrm{C}$. After rinsing with HBSS, sections were incubated for 1 hour with goat anti-rabbit IgG antibody conjugated with atto-488 (dilution $1: 200$ ), avoiding direct light. Nuclei were counterstained using $4^{\prime}, 6$ Diamidino-2-Phenylindole (DAPI, dilution 1:1000). Incubation of specimens with DAPI $(5 \mathrm{~min})$ was followed by HBSS washing. Slides were mounted using Fluoromount to image the sections. Specimens were visualized using epifluorescence microscopy (Axio Observer A1, Zeiss) with a 100 -fold magnification. Images were saved and processed using Axio Imager 4.7 software. Nonspecific staining of the samples was reduced by incubation with a blocking buffer for 30 minutes. The incubation buffer contained goat serum $(1: 100)$, bovine albumin $(1: 10)$, and Triton-X (0.3\%).

2.2.3. Detection of OPN in Mice Serum. The OPN concentration was measured using ELISA kit (DuoSet ELISA Development kit; R\&D Systems). Serum was obtained from all control and experimental animals. The test was performed similarly as it was described in paragraph 1.7, with the difference that serum samples required 100-fold dilution. All samples and standards were measured in duplicate.

2.3. Statistical Analysis. The normality of the population data was determined using Shapiro-Wilk test, while equality of variances was assessed by Levene's test. Differences between groups were determined using one- or two-way analysis of variance (ANOVA). Statistical analysis was performed with STATISTICA 10.0 software (StatSoft, Inc., Statistica for Windows, Tulsa, OK, USA). Differences with a probability of $P<0.05$ were considered significant.

\section{Results}

\subsection{In Vitro Study}

3.1.1. Phenotypic Characterization of Isolated ASCs and Multipotency Assay. To confirm multipotent and mesenchymal character of isolated stromal cells, immunohistochemical staining and multipotency assay were performed. Analyses were conducted with regard to the recommendations of International Society of Cellular Therapy [39, 40]. Immunohistochemical analysis revealed that ASCs showed a negative reaction with an antibody against the hematopoietic marker, CD45 (Figure 1). In contrast, the cells were positive for mesenchymal markers characteristic for multipotent stromal cells, for example, CD29, CD44, CD73, and CD105 (Figure 1). The multipotency of mice adipose-derived mesenchymal stem cells was confirmed by the positive results of osteoand adipogenic differentiation (Figure 2). ASCs cultured under osteogenic conditions formed extracellular matrix rich in mineral calcium deposits visualized by Alizarin Red staining (Figure 2(b)). In adipogenic cultures after 14 days of stimulation the formation of lipid droplets was observed (Figure 2(c)).

3.1.2. Proliferation Activity (PA) of Adipose-Derived Stem Cells In Vitro. The proliferation activity of ASCs in vitro, after exposition to the investigated concentrations of metformin, was evaluated after 24, 48, and 72 hours of culture (Figure 3 ). Determination of cell activity in control culture demonstrated that during the first $48 \mathrm{~h}$ the growth of cells was exponential. Between 48 and 72 hours of the culture, the growth rate declined, implying stationary phase of growth. Proliferation of ASCs cultures significantly decreased after $48 \mathrm{~h}$ of exposition to the metformin. The inhibition of ASCs cell growth by metformin occurred in a dose-dependent manner. Despite the fact that proliferation rate of ASCs in cultures with metformin at concentration equal to $1 \mathrm{mM}$ was significantly lower in relation to the control culture, the growth curve had exponential character. Exposure of ASCs to the $5 \mathrm{mM}$ and $10 \mathrm{mM}$ metformin inhibited growth of cells; however after $72 \mathrm{~h}$ the proliferation activity of cultures was restored but at the level significantly lower than in control cultures. 
Culture of mice ASCs in

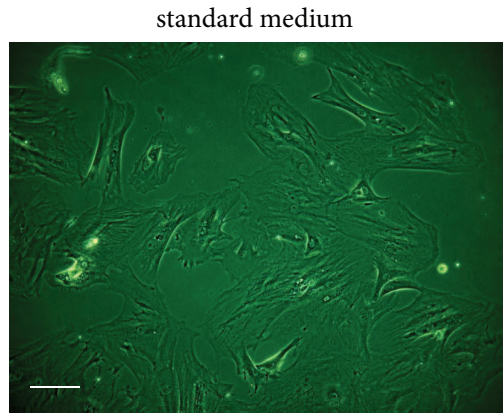

(a)

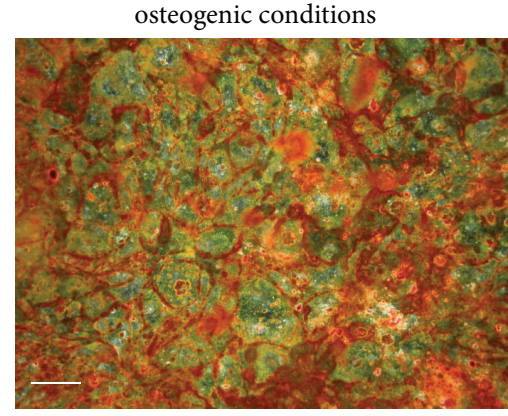

(b)

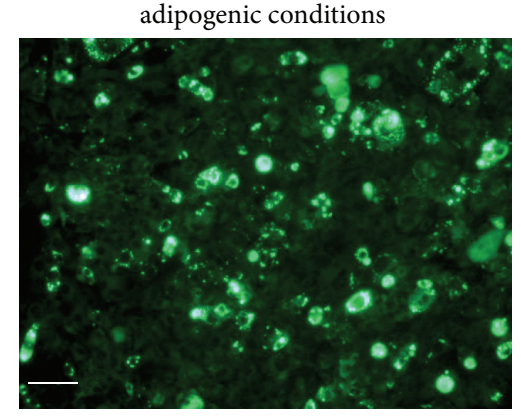

(c)

Figure 2: The morphology of adipose-derived mesenchymal stem cells isolated from subcutaneous fat tissue of mice in standard (a), osteogenic (b) and adipogenic culture (c). The calcium deposits formed in extracellular matrix of osteogenic culture were stained using Alizarin Red. The lipid-rich cellular organelles formed after adipogenic stimulation are visible as green droplets. Images included in the graph were chosen as representative. Both control and experimental cultures were carried out in triplicate. Magnification used is 100x. Scale bar is $200 \mu \mathrm{m}$.

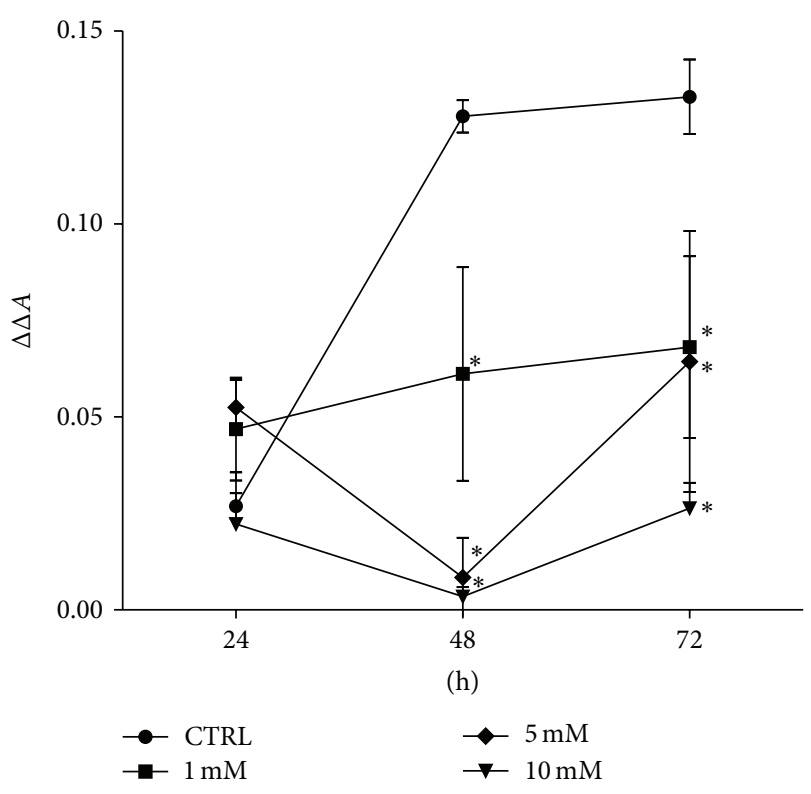

FIgURe 3: Proliferation activity of ASCs after metformin treatment at concentrations of $1 \mathrm{mM}, 5 \mathrm{mM}$, and $10 \mathrm{mM}$ in comparison to the control culture (CTRL). The $X$-axis refers to the time of cells' propagation. The difference between absorbance read at $600 \mathrm{~nm}$ and $690 \mathrm{~nm}$, including absorbance of blank sample, was indicated as $\Delta \triangle A$ mark ( $Y$-axis). The statistical significance $(P<0.01)$ was indicated with asterisk $(*)$. Error bars represent standard deviation from the mean value calculated from three separated measurements.

3.1.3. The Morphology and Ultrastructure of ASCs Treated with Various Concentrations of Metformin. The morphological and ultrastructural changes of ASCs were examined after 24 and $72 \mathrm{~h}$ of the experiment in cultures treated with $1 \mathrm{mM}, 5 \mathrm{mM}$, and $10 \mathrm{mM}$ metformin and compared to the control culture (Figures 4, 6, and 7). The characteristic feature of the obtained ASCs cultures was occurrence of both small and large multipolar fibroblast-like cells (indicated in
Figure 4 with white arrows). Analysis performed using epifluorescence microscope showed that exposure to metformin influenced cells morphology and growth pattern of cultures. In cultures treated with metformin, the large cells were more noticeable. The formation of apoptotic bodies was also more evident and their number was positively correlated with the metformin dose; the increase of apoptotic bodies, visualized with DAPI, was the most significant in culture exposed to $10 \mathrm{mM}$ metformin. The ASCs maintained in control cultures were characterized by the high proliferative activity of cells also expressed by the formation of well-developed monolayer. Cultures treated with metformin were characterized by the irregular pattern of growth, both dispersed, as in cultures exposed to $1 \mathrm{mM}$ metformin, and aggregated, as in culture treated with $5 \mathrm{mM}$ of metformin. The degeneration of ASCs culture was observed after $72 \mathrm{~h}$ as a result of exposure to $10 \mathrm{mM}$ of metformin.

Moreover, the analysis of characteristic signs of cell death, performed after $72 \mathrm{~h}$ of culture, showed that the percentage of dead and apoptotic cells was increasing with the metformin dose (Figure 4: propidium iodide and caspase-3 staining). Additionally, dead cells visualized with propidium iodide were counted. The result of comparative analysis regarding the number of dead cells in experimental versus control culture was shown in Figure 5.

Analysis of cellular junctions formation showed that addition of metformin caused decline of cytoplasmic projection. In the control culture, intercellular connections during the culture period became narrowed, indicating on tight cellcell interaction in formed monolayer. Interactions between plasma membranes of cells in experimental cultures were noticeable only after 24 hours; however connections between cells were not maintained in cultures treated with the drug for 72 hours. Week development of cellular projections was evident especially when $5 \mathrm{mM}$ and $10 \mathrm{mM}$ metformin were used (Figure 6).

The influence of metformin on cells' ultrastructure was expressed mainly by the changes of nuclei shape, size of 
The morphology of ASCs in cultures after

$24 \mathrm{~h}$

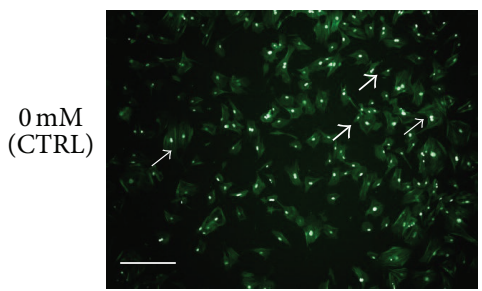

(a)

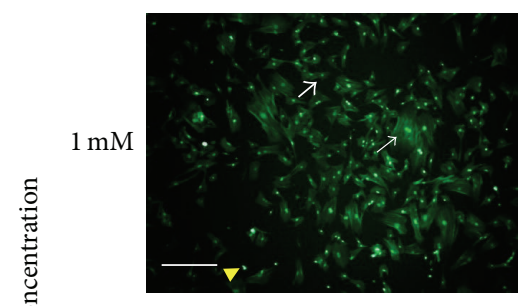

(e)

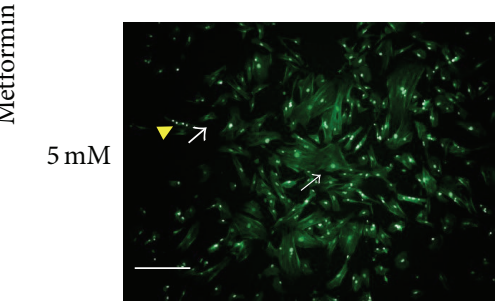

(i)

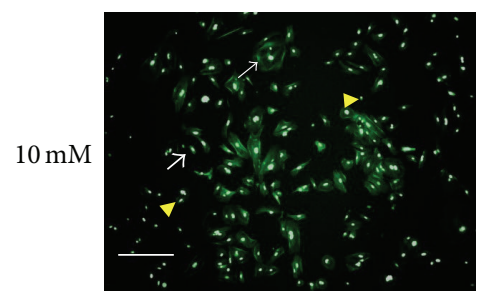

(m)
$72 \mathrm{~h}$

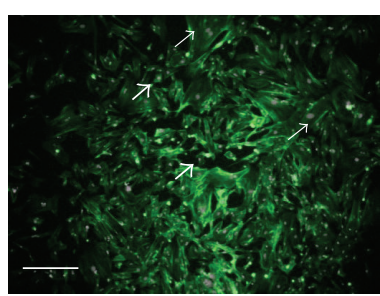

(b)

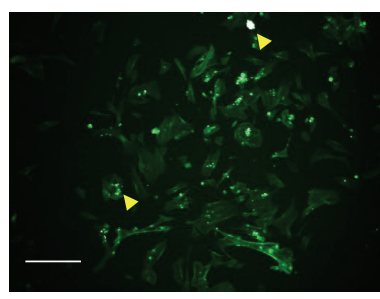

(f)

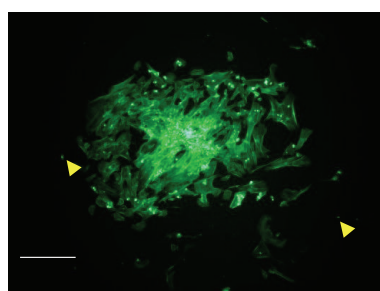

(j)

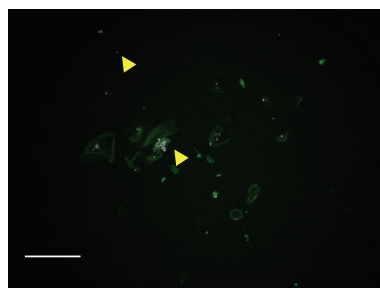

(n)
Detection of dead cells in $72 \mathrm{~h}$ cultures using

propidium iodide

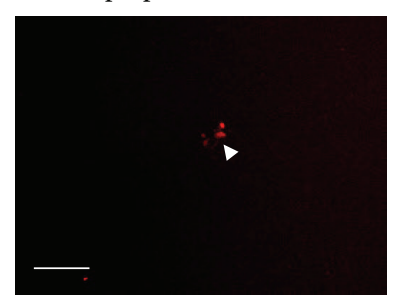

(c)

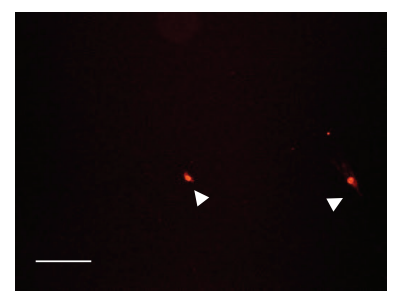

(g)

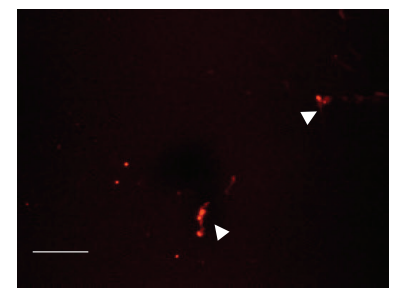

(k)

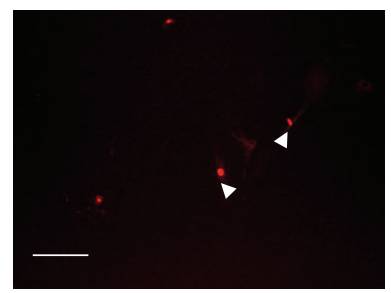

(o) anti-caspase-3 antibody

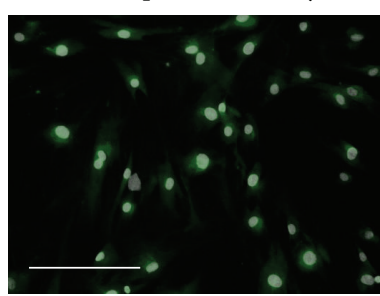

(d)

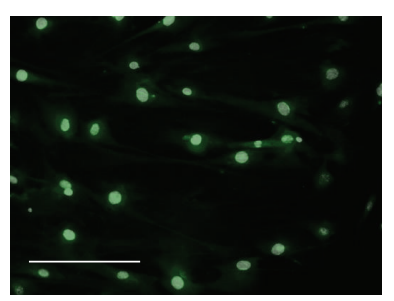

(h)

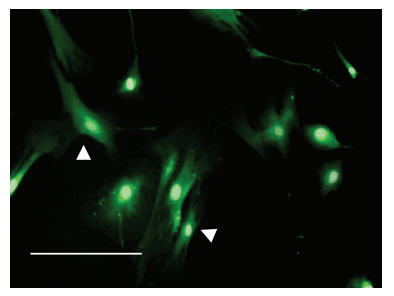

(l)

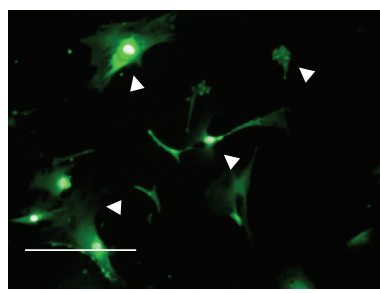

(p)

FIgURE 4: The morphological changes of ASCs after 24 and 72 hours in the cultures treated with $1 \mathrm{mM}((\mathrm{e})$ and (f)), $5 \mathrm{mM}((\mathrm{i})$ and (j)), and $10 \mathrm{mM}((\mathrm{m})$ and $(\mathrm{n}))$ of metformin in comparison to the control cultures $((\mathrm{a})$ and $(\mathrm{b}))$. The graphs provided are representative, showing characteristic features of investigated cultures. The ASCs cultures were characterized by the presence of small (representative indicated with thin arrows) and larger cells (representative indicated with thick arrows). Actin cytoskeleton was visualized using atto- 488 phalloidin (greenstained cell bodies), while nuclei were visualized with DAPI stating (white dots). Apoptotic bodies occurred in cultures were indicated with yellow arrowheads, while dead cells were indicated with white arrowheads. Dead cells identified with propidium iodide are red-stained, while caspase-3 positive cells are green-stained. Magnification used is 50x, and scale bar is $200 \mu \mathrm{m}$.

endosomes and mitochondria, and the number of plasma membrane-derived particles (microvesicles, MVs) shedding (Figure 7). The ultrastructure of ASCs treated with the lowest concentration of metformin was comparable to the ultrastructure of control cells. Cells both derived from control culture and treated with $1 \mathrm{mM}$ of metformin were characterized by the centrally located nuclei surrounded mainly by small, early endosomes and formation of MVs. Cells treated with $5 \mathrm{mM}$ and $10 \mathrm{mM}$ of metformin were characterized by peripherally located nuclei and enlarged, late endosomes. In these cultures, MVs shedding was incidental. Additionally, the ASCs treatment with metformin at concentrations of 5 and $10 \mathrm{mM}$ caused ultrastructural abnormalities in mitochondria (enlargement of mitochondria). Similarly, after $72 \mathrm{~h}$ of culture control cells from control culture and from culture stimulated with $1 \mathrm{mM}$ of metformin shared some common ultrastructural features, like peripheral displacement of nuclei and increased number of MVs. The distinctive feature of cells derived from culture treated with $5 \mathrm{mM}$ was increase of nuclei size, occupying substantial part of cell body, and alteration 


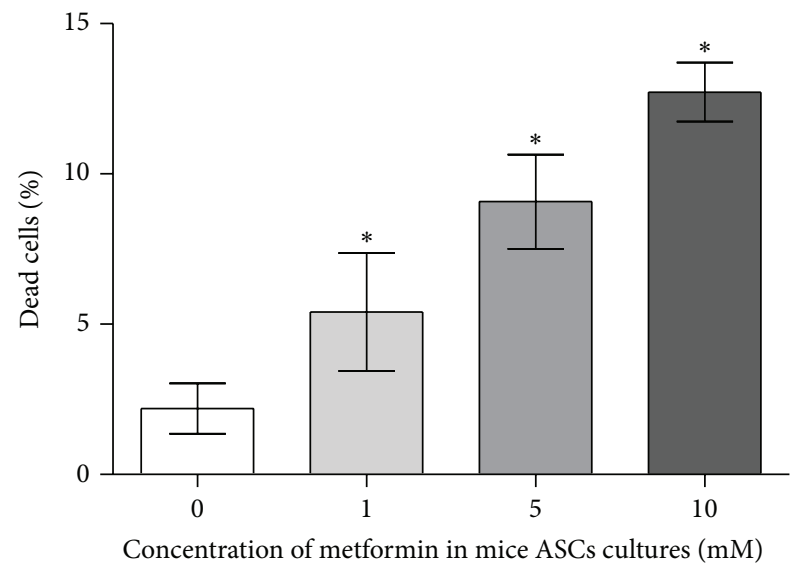

FIGURE 5: The percentage of dead cells, detecetd using Cellstain Double Staining Kit after $72 \mathrm{~h}$ of ASCs culture treated with $1 \mathrm{mM}$, $5 \mathrm{mM}$, and $10 \mathrm{mM}$ of metformin in comparison to the control culture (0 $\mathrm{mM}$ of metformin).

of its shape. Additionally, the enlargement and bulging of mitochondria were maintained. Ultrastructural organization of ASCs treated with $10 \mathrm{mM}$ was disrupted. Degenerative changes of ASCs, treated with the highest dose of the drug, involved invagination and disintegration of cellular membrane, excessive accumulation of endocytic vesicles, and disintegration of cell nuclei (Figure 7).

3.1.4. Detection of OPN at the mRNA and Protein Level in ASC Cultures. Analysis of OPN gene expression was investigated in cells derived from experimental and control cultures, after $24 \mathrm{~h}$ and $72 \mathrm{~h}$ of propagation (Figure 8). Quantitative analysis of transcripts revealed that the expression of OPN in ASCs after $24 \mathrm{~h}$ treated with $1 \mathrm{mM}$ and $5 \mathrm{mM}$ of metformin decreased in comparison to the OPN mRNA expression in control culture; however observed differences were not statistically significant. The propagation of ASCs with $10 \mathrm{mM}$ metformin for $24 \mathrm{~h}$ caused significant inhibition of OPN mRNA expression. Expression of OPN mRNA level was elevated after $72 \mathrm{~h}$, when treated with $1 \mathrm{mM}$; however the increase was not statistically significant. Inhibition of OPN mRNA expression at significant level was noted in cultures maintained for $72 \mathrm{~h}$ with $5 \mathrm{mM}$ and $10 \mathrm{mM}$ of metformin.

The level of secreted metformin in experimental cultures decreased in time and in dose-dependent manner, while in control cultures highest concentration of OPN protein was noted after $72 \mathrm{~h}$ of culture. The concentration of OPN decreased significantly in all experimental cultures after $48 \mathrm{~h}$ of propagation (Figure 9).

\subsection{In Vivo Study}

3.2.1. Clinical Characterization of Animals. In our experiment, administration of metformin caused significant weight loss in C57BL/6 mice. Additionally, mice treated with metformin had lowered glucose and triglyceride levels, whereas
TABLE 1: Results of clinical characterization of animals used for the experiment.

\begin{tabular}{lcc}
\hline Parameters & $\begin{array}{c}\text { Control } \\
\text { group } \\
(n=9)\end{array}$ & $\begin{array}{c}\text { Experimental } \\
\text { group } \\
(n=9)\end{array}$ \\
\hline Body weight $(\mathrm{g})$ & $19.62 \pm 0.55$ & $18.34 \pm 0.53$ \\
Fasting blood glucose $(\mathrm{mmol} / \mathrm{L})$ & $13.30 \pm 0.43$ & $12.70 \pm 0.26$ \\
Fasting serum triglyceride $(\mathrm{mmol} / \mathrm{L})$ & $0.62 \pm 0.05$ & $0.53 \pm 0.03$ \\
Fasting serum cholesterol $(\mathrm{mmol} / \mathrm{L})$ & $1.34 \pm 0.02$ & $1.45 \pm 0.03$ \\
\hline
\end{tabular}

cholesterol level increased (Table 1). All differences observed were statistically significant $(P<0.001)$.

3.2.2. Morphology and Morphometry of Adipocytes. Evaluation of the adipocytes morphology and results of morphometric analyses are shown in Figure 10. Histological examination of abdominal subcutaneous fat tissue collected from mice treated with metformin and from control animals revealed significant morphological changes regarding size of cells and their organization in the tissue. Adipocytes forming adipose tissue of control mice were larger $(16.95 \pm 1.21 \mu \mathrm{m})$ than adipocytes of experimental mice $(13.97 \pm 2.01 \mu \mathrm{m})$. The areas of adipocytes derived from experimental animals were also smaller than in control group. Additionally, population of adipocytes in tissue of control mice was more homogenous both in size (within a range of 15.46-18.67 $\mu \mathrm{m}$ ) and in shape (mainly polygonal), while adipocytes forming adipose tissue of experimental mouse had divergent size (within a range of $11.02-18.21 \mu \mathrm{m}$ ) and morphology. The formation of crownlike structures in adipose tissue of experimental animals was more evident; however comparative analysis of CLS number showed that difference between groups is not relevant.

3.2.3. Fluorescence Immunohistochemistry. The immunohistochemical analysis of subcutaneous fat tissue collected from animals treated with metformin and control animals demonstrated positive reaction for the following markers: CD105, CD44, OPN, Ki67, and caspase-3 (CASP-3). However, substantial differences in the quality and intensity of reaction between investigated groups were observed; results were presented in Figure 11. Fat biopsies of control animals exhibited stronger reaction for $\mathrm{CD}_{4} 4^{+}$and $\mathrm{CD}_{105}{ }^{+}$(Figures 11(b)and 11(f), resp.) in comparison to animals treated with metformin (Figures 11(d) and 11(h)). The expression of OPN in the fat tissue of animals treated with metformin was weaker (Figure 11(1)) when compared to the control animals (Figure 11(j)). The reaction with Ki67 antigen was also more abundant in the fat biopsies of control animals (Figure 11(n)) than in tissues obtained from experimental animals (Figure 11(p)). In turn, the expression of caspase-3 staining in the fat tissue of animals treated with metformin was higher (Figure 11(t)), when compared to the tissue derived from control animals (Figure 11(r)).

3.2.4. Determination of OPN Level in Serum. Evaluation of OPN serum concentration measured with ELISA showed that 

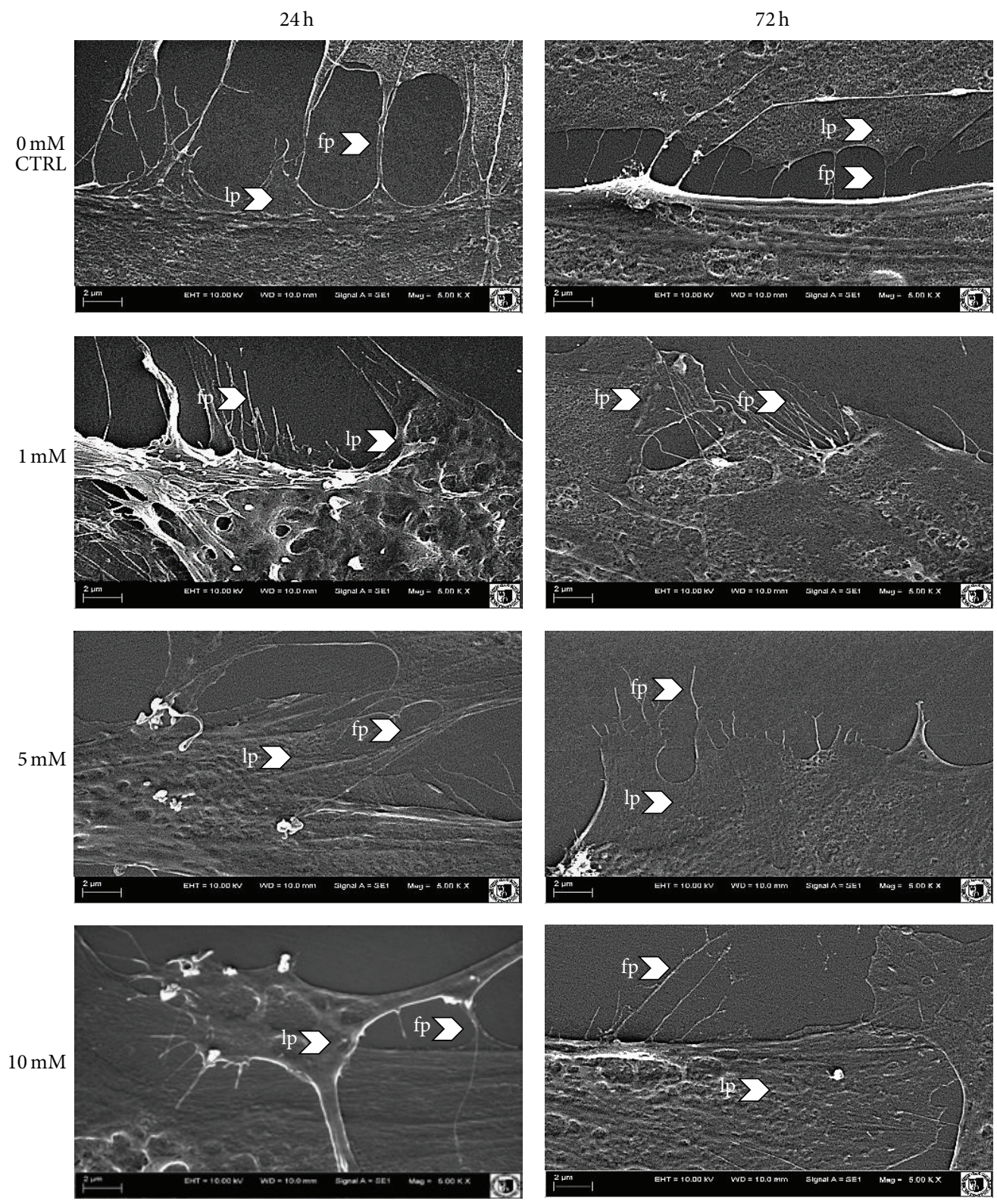

Figure 6: Analysis of cell surface morphology derived from experimental and control culture after $24 \mathrm{~h}$ and $72 \mathrm{~h}$ of propagation. Cellular projections were indicated with arrows (LP: lamellipodia and FP: filopodia). Depicted images are representative and were obtained from cultures carried out in duplicate.

mice treated with metformin exhibit significantly lower OPN level than mouse in control group. The results of statistical analysis are presented in Figure 12.

\section{Discussion}

In the present study we investigated the effects of metformin on adipose-derived mesenchymal multipotent stromal cells (ASCs) and adipocytes, especially in relation to their proliferative potential. We have also focused on the evaluation of the influence of metformin on the morphology of both cells population of adipose tissue, and thus the results presented here include in vitro and in vivo studies. Metformin is known mainly for its antidiabetic properties, but it may also produce physiological effects comparable to calorie restriction. For instant, it may decrease fat mass and reduce size of adipocytes, as it was shown in depots of subcutaneous tissue of patients with diabetes [41, 42]. Additionally, it has been shown in in vitro studies that metformin may increase glucose uptake of adipocytes and embryonic tissues $[43,44]$. Because glucose is a crucial nutrient for proliferating cells, it was of our interest whether metformin has an effect on proliferation of adipocytes precursors (ASCs) and adipocytes. The application of ASCs for regenerative medicine becomes more 

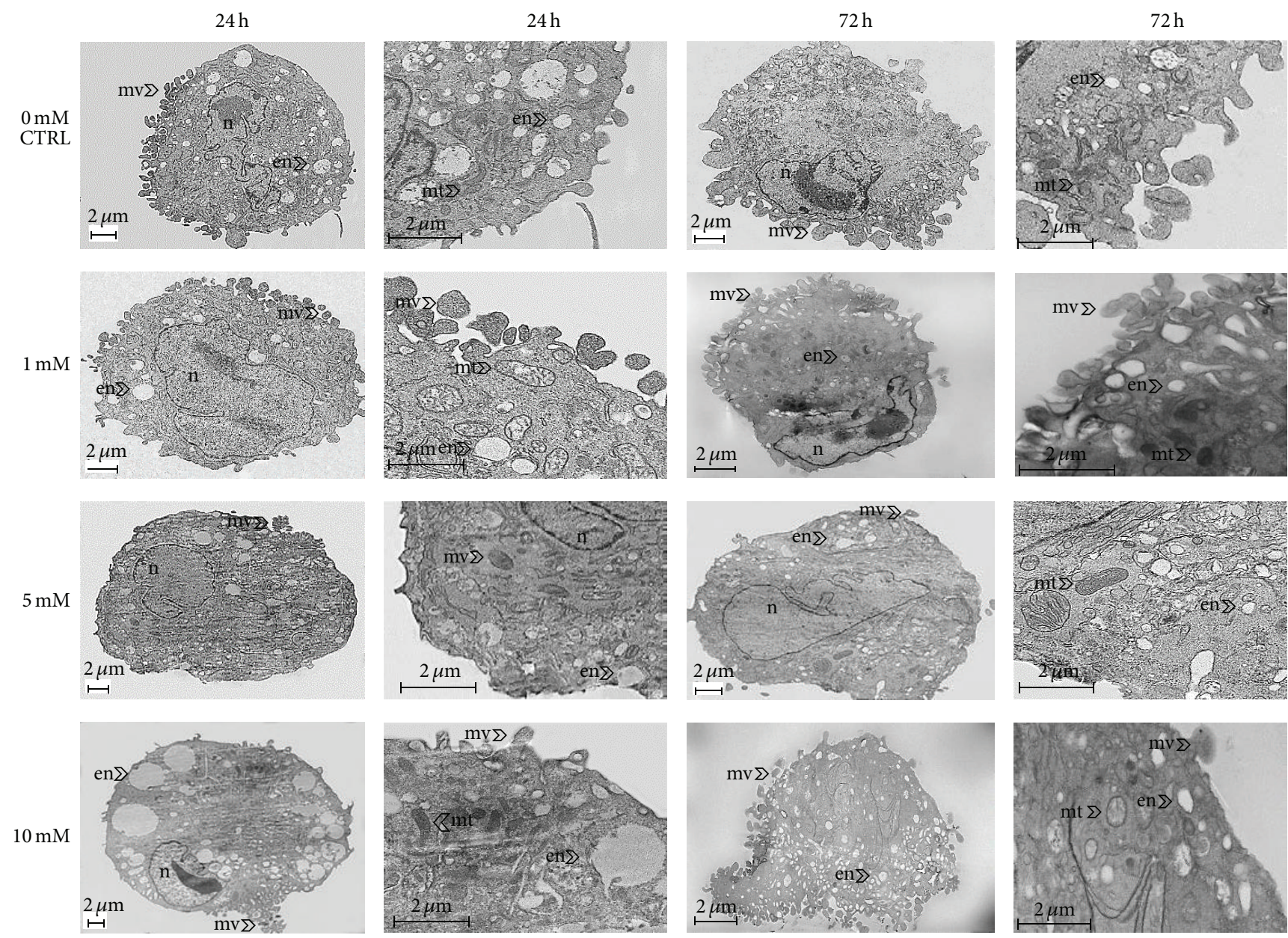

FIGURE 7: The ultrastructural changes of mice ASCs after 24 and 72 hours in the cultures treated with $1 \mathrm{mM}, 5 \mathrm{mM}$, and $10 \mathrm{mM}$ of metformin in comparison to the control culture. Typical ultrastructural features were indicated with proper abbreviations: nu: nucleus, en: endosomes, mv: microvesicles, and mt: mitochondria. Depicted images are representative, and were obtained from cultures carried out in duplicate.

and more frequently investigated in both basic biological research, fundamental in context of establishing of ASCs cytophysiology, and preclinical studies [45].

As it was previously shown, metformin may inhibit proliferation of stromal cells-fibroblasts [46] and cancer cells by activation of AMPK and inhibition of multiple molecular signaling pathways, which are important in protein synthesis control [47-49]. The field of our interest was to evaluate the influence of metformin on the expression of osteopontin which is a multifunctional protein involved in various inflammatory processes, cell proliferation and migration, and tissue remodeling [50].

When comparing proliferation activity of ASCs in vitro in experimental and control cultures with the supernatant concentration of OPN measured with ELISA, we have found similarity in the pattern of curves' course. In the first 24 hours of cultures the proliferation activity of cells and OPN concentration in all investigated groups were at the same level. Both proliferation and OPN concentration significantly decreased after $48 \mathrm{~h}$ in cultures exposed to the metformin. Inhibition of proliferation activity of cells was also correlated with OPN decrease at mRNA level; the transcript level depends on dose used in culture, and the lowest expression of OPN mRNA was noted in cultures treated with $10 \mathrm{mM}$ of metformin.

Inhibited expression of OPN gene along with other osteogenic markers after treatment with metformin was noted previously in primary osteoblasts and mouse osteoblastic cell line (MC3T3-E1) [51]. In this paper, the authors revealed that osteogenic differentiation was downregulated significantly by $2 \mathrm{mM}$ of metformin and also due to glucose restriction. This occurrence was associated by the authors with AMPK activity, as its phosphorylation was induced by metformin. Additionally it was proven that sustained phosphorylation of AMPK was well correlated with the inhibition of matrix mineralization. The authors of this paper revealed that phosphorylation of AMPKa in osteoblasts caused by metformin strongly depends on its dose, which is very important.

The metformin action in time- and dose-dependent manner was also noticed by the other researcher groups in various cell cultures. The concentrations of metformin which was used in this study were also tested in cultures of human 


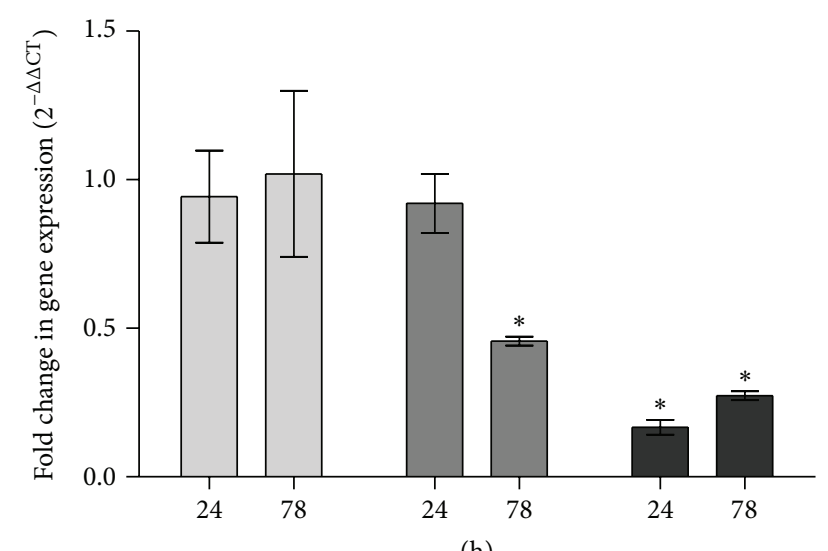

(h)

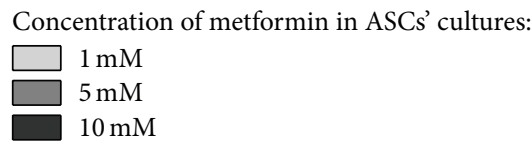

FIgURE 8: Expression of mRNA for OPN in experimental cultures. Quantification of relative values was performed using $2^{-\Delta \Delta C T}$ method, normalizing data to control culture and including expression of reference gene. Data are presented as the mean fold change of relative expression and compared to control cultures (normalized to 100\%); error bars represent standard deviation from the mean calculated for normalized values obtained in three separate reactions; asterisks represent statistically significant differences $(P<$ $0.05)$.

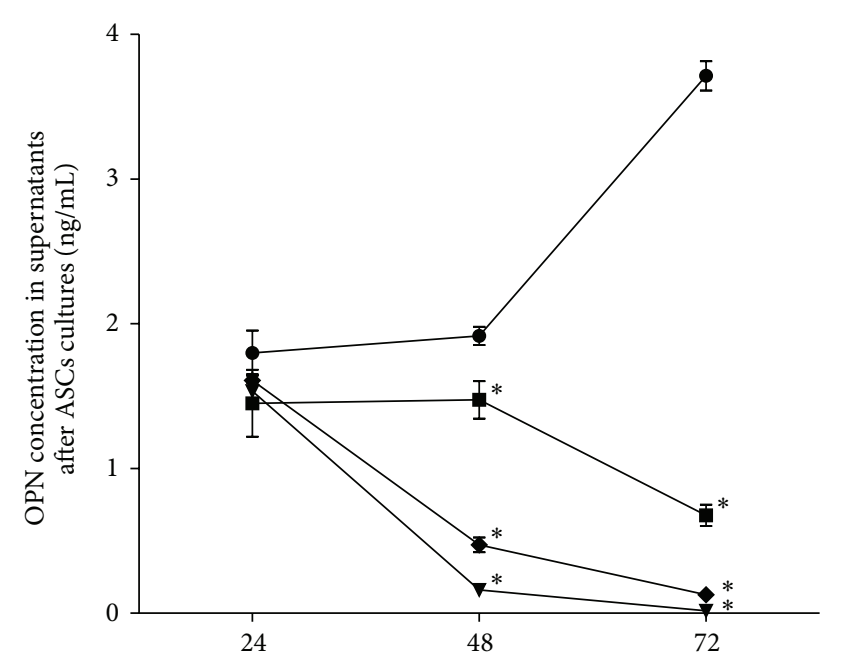

(h)

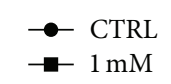

$$
\begin{aligned}
& \multimap 5 \mathrm{mM} \\
& \multimap 10 \mathrm{mM}
\end{aligned}
$$

FIGURE 9: The mean concentration of OPN protein in the control (CTRL) and experimental cultures $(1 \mathrm{mM}, 5 \mathrm{mM}$, and $10 \mathrm{mM}$ metformin) determined in supernatants collected at specific time of cultures ( $X$-axis). The statistically significant decrease of OPN protein was shown at $48 \mathrm{~h}$ and $72 \mathrm{~h}$ after treatment with $5 \mathrm{mM}$ and $10 \mathrm{mM}$ and in all experimental groups, respectively. The statistically significant difference determined in relation to the results obtained for control group was indicated with asterisks $\left({ }^{*} P<0.05\right)$. The mean values of OPN concentration were calculated from the results obtained in two measurements. oral squamous cell carcinoma and significantly reduced the colony formation of those cells in vitro [6]. Dose related effects of metformin were also investigated using stromal cells. Recently Abu-Zaiton [46] has shown that metformin at concentration of $100 \mu \mathrm{g} / \mathrm{mL}$ inhibits fibroblast proliferation, at both the normoxia and hypoxia conditions. Gao et al. [52] showed also that metformin may negatively influence adipogenic differentiation of progenitor cells isolated from bone marrow. Interestingly, the effects of metformin on stromal cells were tested at concentrations lower than doses used in experiments showing antitumor effect of this drug $[46,52,53]$. The antitumor effect of metformin investigated in vitro was established for doses from 5 to $30 \mathrm{mM}$ [1, 4$6,54]$. These concentrations of metformin tested on cancer cell cultures are considered as well above the concentration in which metformin can be safely used in vivo $[30,55]$. But another point of view was stated by Wilcock and Bailey [31]. It was shown that the levels of metformin that accumulate in the tissues might be several times higher than in the blood, and thus metformin acts at a significantly higher level in the target organs.

Additionally, results of microscopic evaluation of ASCs morphology and ultrastructure have shown that high doses of metformin ( $5 \mathrm{mM}$ and $10 \mathrm{mM}$ ), which were used for in vitro studies, possess a cytotoxic effect on the cells and may cause (i) disintegration of cells, (ii) nucleus fragmentation and production of apoptotic bodies, (iii) enlargement of mitochondria, (iv) inhibition of MVs shedding, and (v) limited development of cellular projections. To the best of our knowledge, this is the first report describing morphological and ultrastructural changes of ASCs under the influence of metformin. However the observations concerning ultrastructural alterations resulting from the metformin action are consistent with the descriptions presented by Pounaghi et al. [56] who have noticed shape shrinking and size decreasing of granulosa cells, as well as nuclei shrinking and reduction in number of cytoplasmic organelles and their unnatural appearance. Interestingly, the enlargement of mitochondria observed in ASCs treated with $5 \mathrm{mM}$ of metformin is a feature which was noticed also in granulosa cells and nontransformed breast epithelial cells [56, 57].

Kiefer et al. [58] have noticed that osteopontin is strongly upregulated in adipose tissue of high-fat diet-induced and genetically obese mice. Our results show that osteopontin expression in adipose tissue of mice treated with metformin decreased in comparison with control group, not receiving metformin. The decrease of tissue OPN expression was correlated with the decrease of other investigated markers of proliferating cells, that is, Ki-67 and CD105. Both Ki67 and CD105 are proteins essential for cells proliferation [59]. The downregulation of Ki-67 expression resulting from metformin treatment was noted previously in breast and ovarian tumors [60]. Ki-index is highly correlated with cancer progression as it is strongly expressed by proliferating cancer cells. Recently, Tebbe et al. [60] have shown that metformin limits adipocyte mediated ovarian cancer cell proliferation, migration, and expression of cancer associated genes and bioenergetic changes. The inhibition of adipocytes proliferative potential was associated with inhibition of 


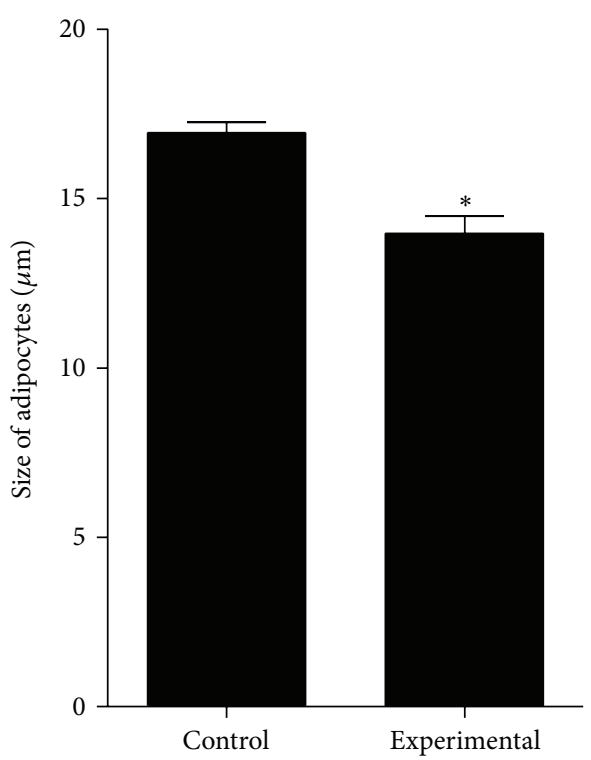

(a)
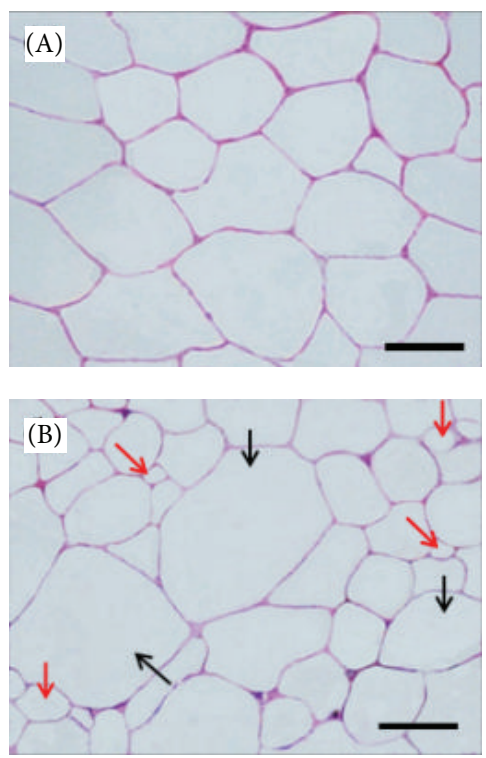

(c)

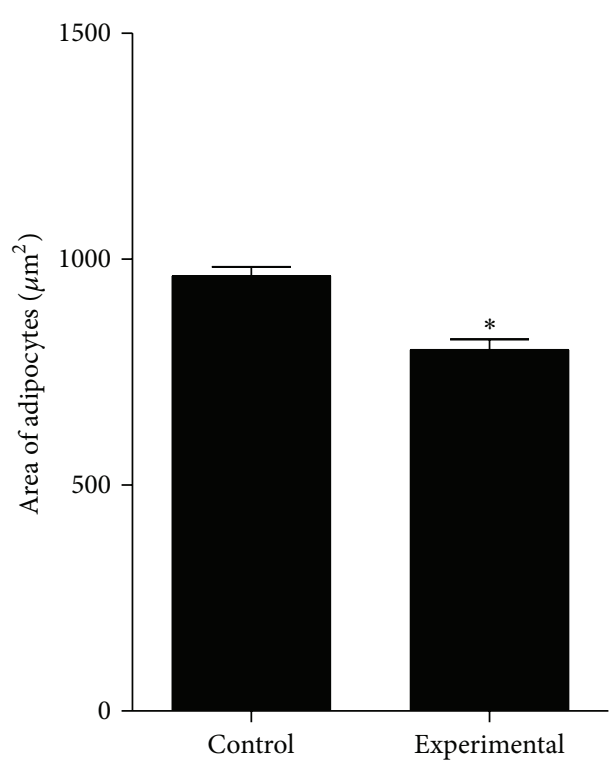

(b)

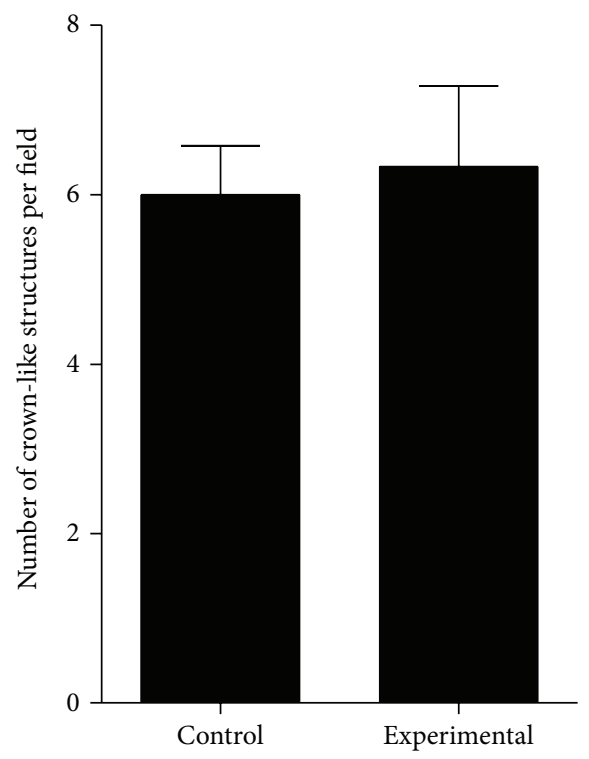

(d)

FIGURE 10: The results of morphometric analyses: comparison of the adipocytes size (a) and areas (b) in tissue of control and experimental group. Differences in cells dimensions were statistically significant at $P<0.05(*)$. Morphometric analysis of adipocytes was performed on six sections separately. Calculations were expressed as a mean value ( $Y$-axis). (c) The results of hematoxylin-eosin (H-E) staining of adipose tissue sections derived from control group (A) and experimental group (B). Diversity of adipocytes in tissue of mice treated with metformin was indicated with arrows: red is indicating cells smaller in size and black is indicating cells of larger size. Scale bar is $75 \mu \mathrm{m}$. (d) The results of crown-like structures determination performed on six different microscopic images. Crown-like structures are visible in sections as aggregated macrophages accumulated and fused around adipocytes.

Ki-67 expression in differentiating adipocytes. Paper of Tebbe et al. [60] supported the thesis that metformin inhibits differentiation of murine preadipocytes, stated previously by the other authors $[61,62]$. Our results are in good agreement with this postulate, because in the adipose tissue of mice treated with metformin the decrease of CD105 protein expression was noted. Moreover, after metformin treatment, we have observed the increased expression of caspase- 3 in adipose tissue biopsies. As it was previously shown, inhibitory effect of metformin on cancer cells may be the result of activation of caspase-dependent apoptosis $[63,64]$. Therefore, obtained results of immunostaining assay show that metformin not only may inhibit self-renewal properties of adipocytes, but also may induce their death.

Additionally, in our model, the decrease of tissue OPN expression after metformin treatment correlated also with 


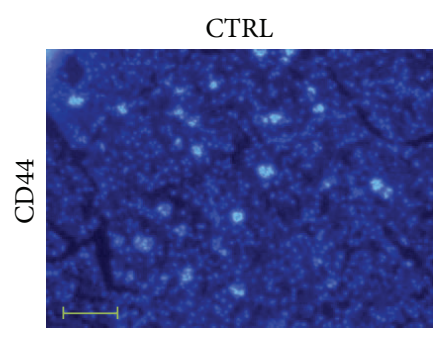

(a)

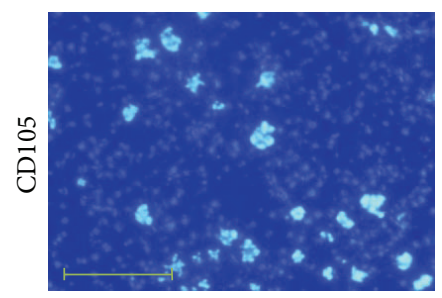

(e)

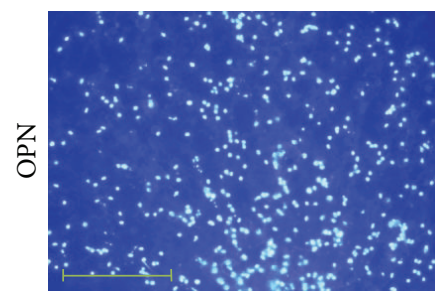

(i)

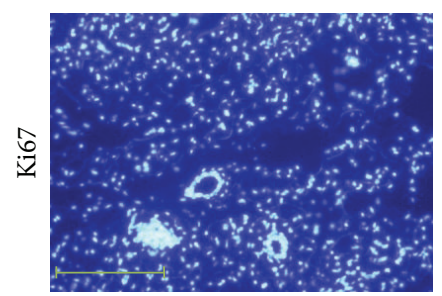

(m)

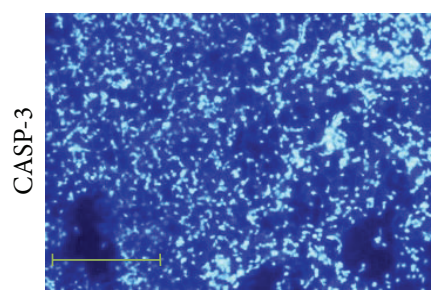

(q)

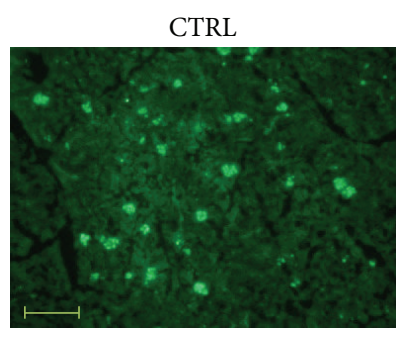

(b)

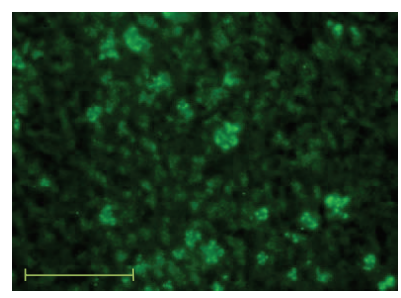

(f)

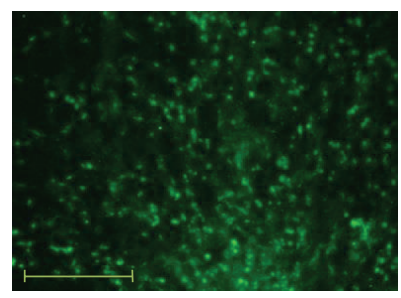

(j)

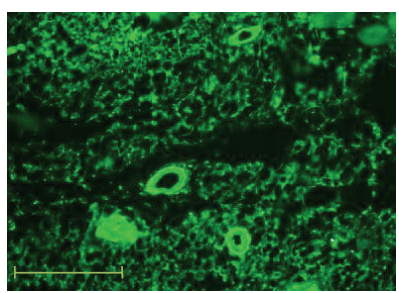

(n)

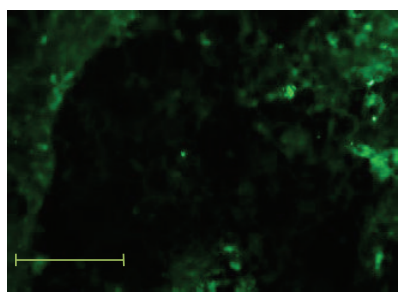

(r)

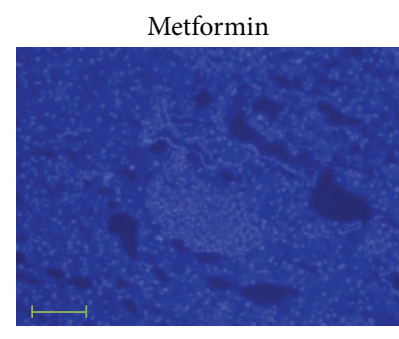

(c)

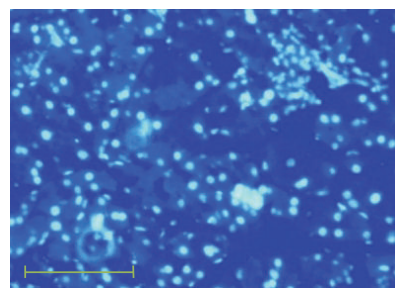

(g)

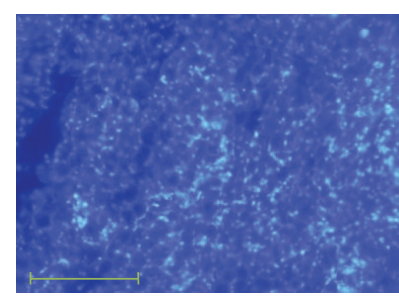

(k)

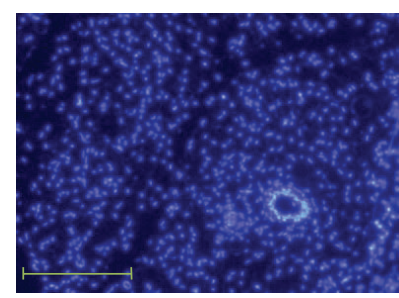

(o)

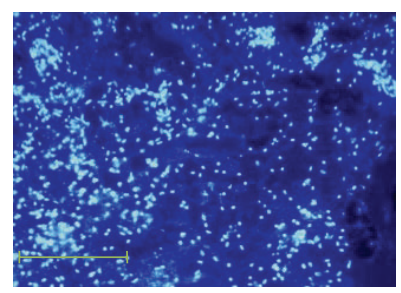

(s)

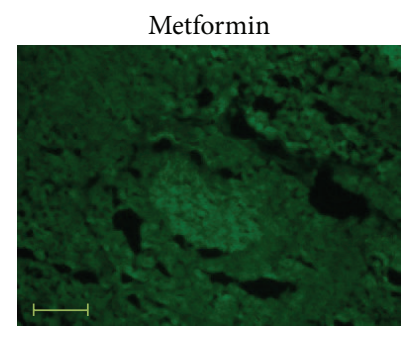

(d)

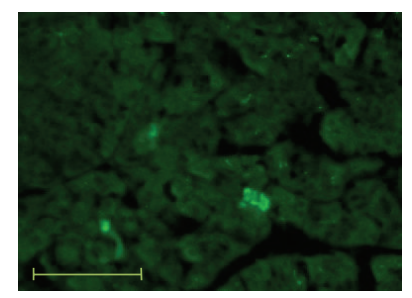

(h)

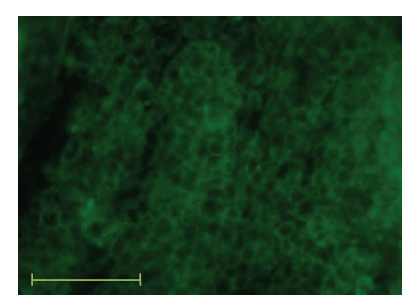

(1)

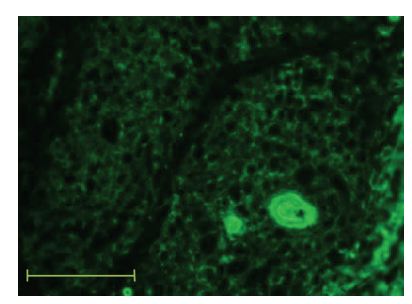

(p)

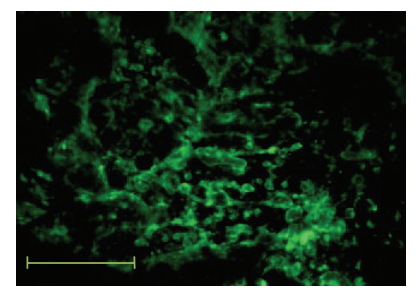

(t)

FIGURE 11: Results of immunohistochemical staining for CD44, CD105, OPN, Ki67, and caspase-3 (CASP-3). In order to recognize the nuclei location, the images of specific staining were arranged with images presenting results of DAPI staining (blue-tone images). The weaker CD44 ${ }^{+}$, $\mathrm{CD}_{105}{ }^{+}, \mathrm{OPN}^{+}$, and $\mathrm{Ki}_{67}$ reactions were noted in subcutaneous fat tissues collected from experimental group. Stronger positive reaction for caspase- 3 was seen in fat biopsies derived from animals treated with metformin than in control group. Immunostaining reactions were prepared in duplicate. Magnifications are 50x and 100x; scale bar is $400 \mu \mathrm{m}$.

decreased levels of this protein in mice serum. Number of human studies reported elevated circulating OPN levels in obese individuals compared with lean subjects [50]. Surprisingly, results presented by Kiefer et al. [58] and You et al. [65] showed that circulating levels of OPN do not correspond with OPN expression in adipose tissue of individuals with diet-induced obesity, in both mice and humans. Results of Kiefer et al. [58] and You et al. [65] indicate that local concentrations of OPN in adipose tissue may not affect its systemic levels. Based on the results obtained in our model, it can be concluded that metformin regulates both local and systemic OPN levels. 


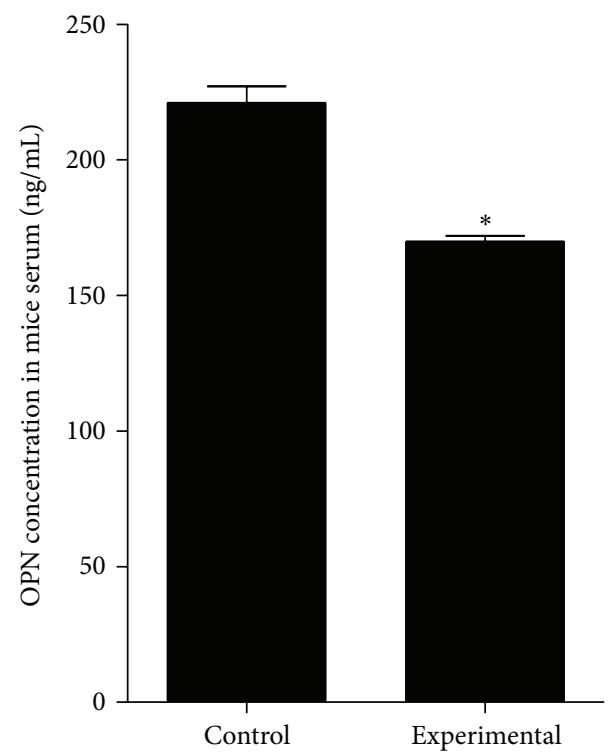

FIGURE 12: The concentration of OPN protein in the serum of mice derived from control and experimental-metformin treated group. Mean values express osteopontin level of nine mice belonging to the investigated group. The statistically significant decrease of OPN protein was noted in serum of experimental animals. The statistically significant difference determined in relation to the results obtained for control group was indicated with asterisks $\left({ }^{*} P<0.05\right)$.

Our experiment also showed the effect of metformin on an adipocytes size. Morphometric correlation of adipocytes size from adipose tissue of control and experimental group revealed that metformin treatment significantly decreased diameter and area of adipocytes. This observation is in a good agreement with Ciaraldi et al. [41] and Stumvoll et al. [42]. Additionally, we noted that metformin may influence adipose tissue composition, due to the fact that adipose tissue of mouse treated with metformin had more heterogeneous structure.

Quantitative evaluation of crown-like structures occurring around adipocytes revealed that macrophage infiltration into adipose tissue is similar in both investigated groups of animals. The fact that metformin may regulate body weight $[11,12]$ was also evident in our model. Based on the clinical characteristics of animals, metformin reduced body weight. Moreover, metformin influenced glucose and triglyceride levels causing their decrease; however, in contrary to previous reports, our results indicate elevated levels of cholesterol in group receiving metformin $[66,67]$.

\section{Conclusions}

In conclusion, metformin affects morphology of adiposederived multipotent mesenchymal stem cells and adipocytes. Moreover, this compound highly influences proliferation of cells derived from adipose tissue. Targeting OPN expression and synthesis by the metformin action may significantly inhibit proliferation and differentiation of adipocytes and adipocytes precursors. Because obesity, cancer, and aging have numerous interrelationships, the recognition of metformin influence on OPN expression may bring a key that will help to tackle epidemics of obesity, diabetes, and cancer. Additionally, dose titration of metformin appears to be crucial, as effects of metformin action strongly relates to its concentration. An important part of future studies, related to metformin effects on stromal cells, should be a detailed analysis of the mechanisms of its action. As it was previously noted, the inhibitory effect of metformin on cells proliferation and differentiation may vary among cells. It seems that a strong clue that will allow for clarification of this issue might be elucidation of AMPK role in these cellular processes.

\section{Conflict of Interests}

There is no conflict of interests.

\section{Acknowledgments}

The research was supported by Wroclaw Research Centre EIT+ under the Project "Biotechnologies and advanced medical technologies", BioMed (POIG.01.01.02-02-003/08) financed from the European Regional Development Fund (Operational Program Innovative Economy, 1.1.2). Additionally, we acknowledge the Leading National Research Centre "KNOW" (Krajowy Naukowy Ośrodek Wiodący) for covering the publication fee.

\section{References}

[1] I. N. Alimova, B. Liu, Z. Fan et al., "Metformin inhibits breast cancer cell growth, colony formation and induces cell cycle arrest in vitro," Cell Cycle, vol. 8, no. 6, pp. 909-915, 2009.

[2] W. H. Gotlieb, J. Saumet, M.-C. Beauchamp et al., "In vitro metformin anti-neoplastic activity in epithelial ovarian cancer," Gynecologic Oncology, vol. 110, no. 2, pp. 246-250, 2008.

[3] E. Giovannucci, D. M. Harlan, M. C. Archer et al., "Diabetes and cancer: a consensus report," Diabetes Care, vol. 33, no. 7, pp. 1674-1685, 2010.

[4] E. Karnevi, K. Said, R. Andersson, and A. H. Rosendahl, "Metformin-mediated growth inhibition involves suppression of the IGF-I receptor signalling pathway in human pancreatic cancer cells," BMC Cancer, vol. 13, article 235, 2013.

[5] B. Liu, Z. Fan, S. M. Edgerton et al., "Metformin induces unique biological and molecular responses in triple negative breast cancer cells," Cell Cycle, vol. 8, no. 13, pp. 2031-2040, 2009.

[6] Q. Luo, D. Hu, S. Hu, M. Yan, Z. Sun, and F. Chen, "In vitro and in vivo anti-tumor effect of metformin as a novel therapeutic agent in human oral squamous cell carcinoma," BMC Cancer, vol. 12, article 517, 2012.

[7] V. N. Anisimov, L. M. Berstein, I. G. Popovich et al., "If started early in life, metformin treatment increases life span and postpones tumors in female SHR mice," Aging, vol. 3, no. 2, pp. 148-157, 2011.

[8] K. S. Rana, H. R. Griffiths, P. Navas, and J. E. Brown, "The interaction between metabolic disease and ageing," Global Journal of Obesity, Diabetes and Metabolic Syndrome, vol. 1, no. 1, p. 102, 2014. 
[9] F. Bednar and D. M. Simeone, "Metformin and cancer stem cells: old drug, new targets," Cancer Prevention Research, vol. 5, no. 3, pp. 351-354, 2012.

[10] B. Viollet, B. Guigas, N. Sanz Garcia, J. Leclerc, M. Foretz, and F. Andreelli, "Cellular and molecular mechanisms of metformin: an overview," Clinical Science, vol. 122, no. 6, pp. 253-270, 2012.

[11] A. Lee and J. E. Morley, "Metformin decreases food consumption and induces weight loss in subjects with obesity with type II non-insulin-dependent diabetes," Obesity Research, vol. 6, no. 1, pp. 47-53, 1998.

[12] Y. Matsui, Y. Hirasawa, T. Sugiura, T. Toyoshi, K. Kyuki, and M. Ito, "Metformin reduces body weight gain and improves glucose intolerance in high-fat diet-fed C57BL/6J Mice," Biological and Pharmaceutical Bulletin, vol. 33, no. 6, pp. 963-970, 2010.

[13] S. Srinivasan, G. R. Ambler, L. A. Baur et al., "Randomized, controlled trial of metformin for obesity and insulin resistance in children and adolescents: improvement in body composition and fasting insulin," The Journal of Clinical Endocrinology and Metabolism, vol. 91, no. 6, pp. 2074-2080, 2006.

[14] J. A. Yanovski, J. Krakoff, C. G. Salaita et al., "Effects of metformin on body weight and body composition in obese insulin-resistant children: a randomized clinical trial," Diabetes, vol. 60 , no. 2, pp. 477-485, 2011.

[15] P. C. Baer and H. Geiger, "Adipose-derived mesenchymal stromal/stem cells: tissue localization, characterization, and heterogeneity," Stem Cells International, vol. 2012, Article ID 812693, 11 pages, 2012.

[16] P. C. Baer, "Adipose-derived mesenchymal stromal/stem cells: an update on their phenotype in vivo and in vitro," World Journal of Stem Cells, vol. 6, no. 3, article 256, 2014.

[17] P. A. Zuk, "The adipose-derived stem cell: Looking back and looking ahead," Molecular Biology of the Cell, vol. 21, no. 11, pp. 1783-1787, 2010.

[18] J. M. Gimble, A. J. Katz, and B. A. Bunnell, "Adipose-derived stem cells for regenerative medicine," Circulation Research, vol. 100, no. 9, pp. 1249-1260, 2007.

[19] M. Tobita, H. Orbay, and H. Mizuno, "Adipose-derived stem cells: current findings and future perspectives," Discovery Medicine, vol. 11, no. 57, pp. 160-170, 2011.

[20] A. Banas, "Purification of adipose tissue mesenchymal stem cells and differentiation toward hepatic-like cells," Methods in Molecular Biology, vol. 826, pp. 61-72, 2012.

[21] X.-J. Lv, G.-D. Zhou, Y. Liu et al., "In vitro proliferation and differentiation of adipose-derived stem cells isolated using antiCD105 magnetic beads," International Journal of Molecular Medicine, vol. 30, no. 4, pp. 826-834, 2012.

[22] C. Gerlach, D. Y. Sakkab, T. Scholzen, R. Daßler, M. R. Alison, and J. Gerdes, "Ki-67 expression during rat liver regeneration after partial hepatectomy," Hepatology, vol. 26, no. 3, pp. 573578, 1997.

[23] M. Maumus, C. Sengenès, P. Decaunes et al., "Evidence of in situ proliferation of adult adipose tissue-derived progenitor cells: influence of fat mass microenvironment and growth," The Journal of Clinical Endocrinology and Metabolism, vol. 93, no. 10, pp. 4098-4106, 2008.

[24] A. Rigamonti, K. Brennand, F. Lau, and C. A. Cowan, "Rapid cellular turnover in adipose tissue," PLoS ONE, vol. 6, no. 3, Article ID e17637, 2011.

[25] D. E. Rodriguez, T. Thula-Mata, E. J. Toro et al., "Multifunctional role of osteopontin in directing intrafibrillar mineralization of collagen and activation of osteoclasts," Acta Biomaterialia, vol. 10, no. 1, pp. 494-507, 2014.
[26] D. R. Senger, B. B. Asch, B. D. Smith, C. A. Perruzzi, and H. F. Dvorak, "A secreted phosphoprotein marker for neoplastic transformation of both epithelial and fibroblastic cells," Nature, vol. 302, no. 5910, pp. 714-715, 1983.

[27] P. Lekic, J. Sodek, and C. A. G. McCulloch, "Relationship of cellular proliferation to expression of osteopontin and bone sialoprotein in regenerating rat periodontium," Cell and Tissue Research, vol. 285, no. 3, pp. 491-500, 1996.

[28] H.-J. Cho and H.-S. Kim, "Osteopontin: a multifunctional protein at the crossroads of inflammation, atherosclerosis, and vascular calcification," Current Atherosclerosis Reports, vol. 11, no. 3, pp. 206-213, 2009.

[29] T. Nomiyama, D. Perez-Tilve, D. Ogawa et al., "Osteopontin mediates obesity-induced adipose tissue macrophage infiltration and insulin resistance in mice," Journal of Clinical Investigation, vol. 117, no. 10, pp. 2877-2888, 2007.

[30] M. Foretz, S. Hébrard, J. Leclerc et al., "Metformin inhibits hepatic gluconeogenesis in mice independently of the LKB1/AMPK pathway via a decrease in hepatic energy state," Journal of Clinical Investigation, vol. 120, no. 7, pp. 2355-2369, 2010.

[31] C. Wilcock and C. J. Bailey, "Accumulation of metformin by tissues of the normal and diabetic mouse," Xenobiotica, vol. 24, no. 1, pp. 49-57, 1994.

[32] M. Maredziak, K. Marycz, A. Śmieszek, D. Lewandowski, and N. Y. Toker, "The influence of static magnetic fields on canine and equine mesenchymal stem cells derived from adipose tissue," In Vitro Cellular and Developmental Biology-Animal, vol. 50, no. 6, pp. 562-571, 2014.

[33] K. Marycz, A. Śmieszek, J. Grzesiak et al., "The osteogenic properties of multipotent mesenchymal stromal cells in cultures on $\mathrm{TiO}_{2}$ sol-gel-derived biomaterial," BioMed Research International, vol. 2015, Article ID 651097, 11 pages, 2015.

[34] K. Marycz, A. Śmieszek, J. Grzesiak, A. Donesz-Sikorska, and J. Krzak-Roś, "Application of bone marrow and adipose-derived mesenchymal stem cells for testing the biocompatibility of metal-based biomaterials functionalized with ascorbic acid," Biomedical Materials, vol. 8, no. 6, Article ID 065004, 2013.

[35] R. Starosta, A. Brzuszkiewicz, A. Bykowska et al., "A novel copper (I) complex, $[\mathrm{CuI}$ (2, 2'-biquinoline) $\left.\mathrm{P}\left(\mathrm{CH}_{2} \mathrm{~N}\left(\mathrm{CH}_{2} \mathrm{CH}_{2}\right)_{2} \mathrm{O}\right)_{3}\right]$-synthesis, characterisation and comparative studies on biological activity," Polyhedron, vol. 50, no. 1, pp. 481-489, 2013.

[36] M. Marędziak, K. Marycz, D. Lewandowski, A. Siudzińska, and A. Śmieszek, "Static magnetic field enhances synthesis and secretion of membrane-derived microvesicles (MVs) rich in VEGF and BMP-2 in equine adipose-derived stromal cells (EqASCs) - a new approach in veterinary regenerative medicine," In Vitro Cellular \& Developmental Biology-Animal, vol. 51, no. 3, pp. 230-240, 2015.

[37] P. Chomczynski and N. Sacchi, "Single-step method of RNA isolation by acid guanidinium thiocyanate-phenol-chloroform extraction," Analytical Biochemistry, vol. 162, no. 1, pp. 156-159, 1987.

[38] K. Basinska, K. Marycz, A. Śmieszek, and J. Nicpoń, “The production and distribution of IL- 6 and TNF- $\alpha$ in subcutaneous adipose tissue and their correlation with serum concentrations in Welsh ponies with equine metabolic syndrome," Journal of Veterinary Science, vol. 16, no. 1, pp. 113-120, 2015.

[39] M. Dominici, K. Le Blanc, I. Mueller et al., "Minimal criteria for defining multipotent mesenchymal stromal cells. The International Society for Cellular Therapy position statement," Cytotherapy, vol. 8, no. 4, pp. 315-317, 2006. 
[40] A. Keating, "Mesenchymal stromal cells: new directions," Cell Stem Cell, vol. 10, no. 6, pp. 709-716, 2012.

[41] T. P. Ciaraldi, A. P. S. Kong, N. V. Chu et al., "Regulation of glucose transport and insulin signaling by troglitazone or metformin in adipose tissue of type 2 diabetic subjects," Diabetes, vol. 51, no. 1, pp. 30-36, 2002.

[42] M. Stumvoll, N. Nurjhan, G. Perriello, G. Dailey, and J. E. Gerich, "Metabolic effects of metformin in non-insulindependent diabetes mellitus," The New England Journal of Medicine, vol. 333, no. 9, pp. 550-554, 1995.

[43] M. Fischer, K. Timper, T. Radimerski et al., "Metformin induces glucose uptake in human preadipocyte-derived adipocytes from various fat depots," Diabetes, Obesity and Metabolism, vol. 12, no. 4, pp. 356-359, 2010.

[44] I. W. Smoak, "Glucose metabolism in mouse embryos exposed to metformin in vitro," Toxicology in Vitro, vol. 13, no. 1, pp. 2733, 1999.

[45] H. Mizuno, M. Tobita, and A. C. Uysal, "Concise review: adipose-derived stem cells as a novel tool for future regenerative medicine," Stem Cells, vol. 30, no. 5, pp. 804-810, 2012.

[46] A. S. Abu-Zaiton, "Effect of metformin on proliferation of skin derived stem cells in the case of normoxia and hypoxia," Journal of Biological Sciences, vol. 14, no. 2, pp. 149-153, 2014.

[47] E. J. Gallagher and D. Leroith, "Diabetes, cancer, and metformin: connections of metabolism and cell proliferation," Annals of the New York Academy of Sciences, vol. 1243, no. 1, pp. 54-68, 2011.

[48] Y. K. Choi and K.-G. Park, "Metabolic roles of AMPK and metformin in cancer cells," Molecules and Cells, vol. 36, no. 4, pp. 279-287, 2013.

[49] B. N. M. Zordoky, D. Bark, C. L. Soltys, M. M. Sung, and J. R. B. Dyck, "The anti-proliferative effect of metformin in triplenegative MDA-MB-231 breast cancer cells is highly dependent on glucose concentration: implications for cancer therapy and prevention," Biochimica et Biophysica Acta, vol. 1840, no. 6, pp. 1943-1957, 2014.

[50] F. Kahles, H. M. Findeisen, and D. Bruemmer, “Osteopontin: a novel regulator at the cross roads of inflammation, obesity and diabetes," Molecular Metabolism, vol. 3, no. 4, pp. 384-393, 2014.

[51] T. Kasai, K. Bandow, H. Suzuki et al., "Osteoblast differentiation is functionally associated with decreased AMP kinase activity," Journal of Cellular Physiology, vol. 221, no. 3, pp. 740-749, 2009.

[52] Y. Gao, J. Xue, X. Li, Y. Jia, and J. Hu, "Metformin regulates osteoblast and adipocyte differentiation of rat mesenchymal stem cells," Journal of Pharmacy and Pharmacology, vol. 60, no. 12, pp. 1695-1700, 2008.

[53] X. Shao, X. Cao, G. Song, Y. Zhao, and B. Shi, "Metformin rescues the MG63 osteoblasts against the effect of high glucose on proliferation," Journal of Diabetes Research, vol. 2014, Article ID 453940, 2014.

[54] M. Zakikhani, R. Dowling, I. G. Fantus, N. Sonenberg, and M. Pollak, "Metformin is an AMP kinase-dependent growth inhibitor for breast cancer cells," Cancer Research, vol. 66, no. 21, pp. 10269-10273, 2006.

[55] C. F. Sum, J. M. Webster, A. B. Johnson, C. Catalano, B. G. Cooper, and R. Taylor, "The effect of intravenous metformin on glucose metabolism during hyperglycaemia in Type 2 diabetes," Diabetic Medicine, vol. 9, no. 1, pp. 61-65, 1992.

[56] P. Pounaghi, S. Hasanzadeh, R. A. Sadrkhanlou, and A. A. Farshid, "Ultrastructural study of granulosa cells in ovarian follicles of diabetic and metformin-treated diabetic rats subsequent to induction of exprimental diabetes," Urmia Medical Journal, vol. 23, no. 5, pp. 476-484, 2012.

[57] Y. Zhuang and W. K. Miskimins, "Metformin induces both caspase-dependent and poly(ADP-ribose) polymerasedependent cell death in breast cancer cells," Molecular Cancer Research, vol. 9, no. 5, pp. 603-615, 2011.

[58] F. W. Kiefer, M. Zeyda, J. Todoric et al., "Osteopontin expression in human and murine obesity: extensive local up-regulation in adipose tissue but minimal systemic alterations," Endocrinology, vol. 149, no. 3, pp. 1350-1357, 2008.

[59] P. Mark, M. Kleinsorge, R. Gaebel et al., "Human mesenchymal stem cells display reduced expression of CD105 after culture in serum-free medium," Stem Cells International, vol. 2013, Article ID 698076, 8 pages, 2013.

[60] C. Tebbe, J. Chhina, S. A. Dar et al., "Metformin limits the adipocyte tumor-promoting effect on ovarian cancer," Oncotarget, vol. 5, no. 13, pp. 4746-4764, 2014.

[61] K. B. Alexandre, A. M. Smit, I. P. Gray, and N. J. Crowther, "Metformin inhibits intracellular lipid accumulation in the murine pre-adipocyte cell line, 3T3-L1," Diabetes, Obesity and Metabolism, vol. 10, no. 8, pp. 688-690, 2008.

[62] J. M. Lenhard, S. A. Kliewer, M. A. Paulik, K. D. Plunket, J. M. Lehmann, and J. E. Weiel, "Effects of troglitazone and metformin on glucose and lipid metabolism. Alterations of two distinct molecular pathways," Biochemical Pharmacology, vol. 54, no. 7, pp. 801-808, 1997.

[63] L. W. Wang, Z. S. Li, D. W. Zou et al., "Metformin induces apoptosis of pancreatic cancer cells," World Journal of Gastroenterology, vol. 14, no. 47, pp. 7192-7198, 2008.

[64] Y. Zhuang and W. K. Miskimins, "Metformin induces both caspase-dependent and poly(ADP-ribose) polymerasedependent cell death in breast cancer cells," Molecular Cancer Research, vol. 9, no. 5, pp. 603-615, 2011.

[65] J. S. You, H.-I. Ji, K. J. Chang et al., "Serum osteopontin concentration is decreased by exercise-induced fat loss but is not correlated with body fat percentage in obese humans," Molecular Medicine Reports, vol. 8, no. 2, pp. 579-584, 2013.

[66] P. J. Pentikäinen, E. Voutilainen, A. Aro, M. Uusitupa, I. Penttila, and H. Vapaatalo, "Cholesterol lowering effect of metformin in combined hyperlipidemia: placebo controlled double blind trial," Annals of Medicine, vol. 22, no. 5, pp. 307-312, 1990.

[67] M. G. Wulffelé, A. Kooy, D. de Zeeuw, C. D. A. Stehouwer, and R. T. Gansevoort, "The effect of metformin on blood pressure, plasma cholesterol and triglycerides in type 2 diabetes mellitus: a systematic review," Journal of Internal Medicine, vol. 256, no. 1, pp. 1-14, 2004. 


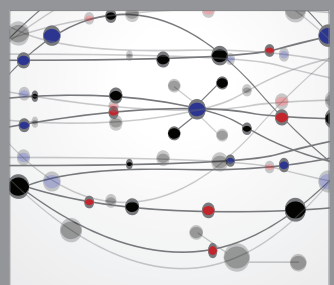

The Scientific World Journal
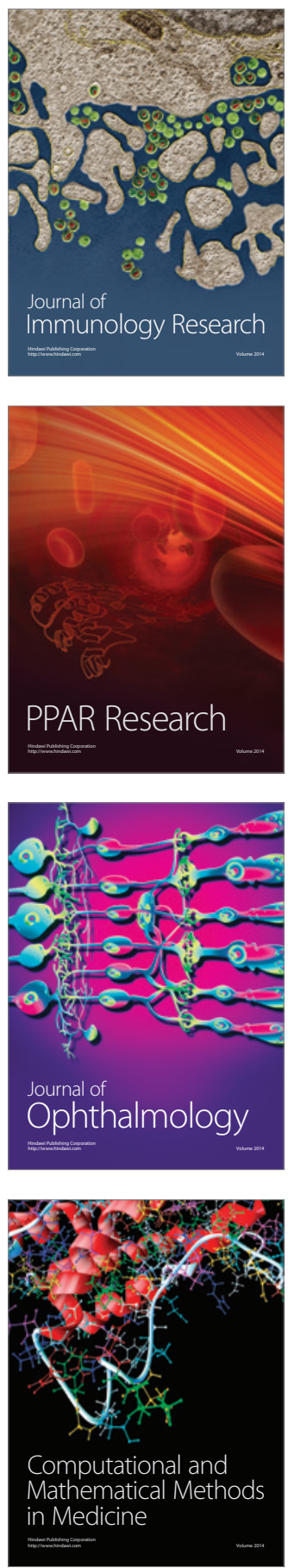

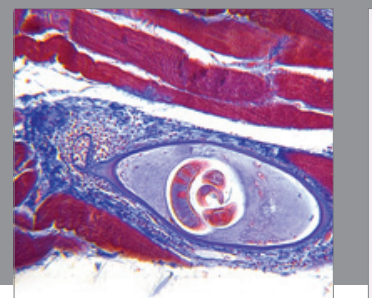

Gastroenterology

Research and Practice
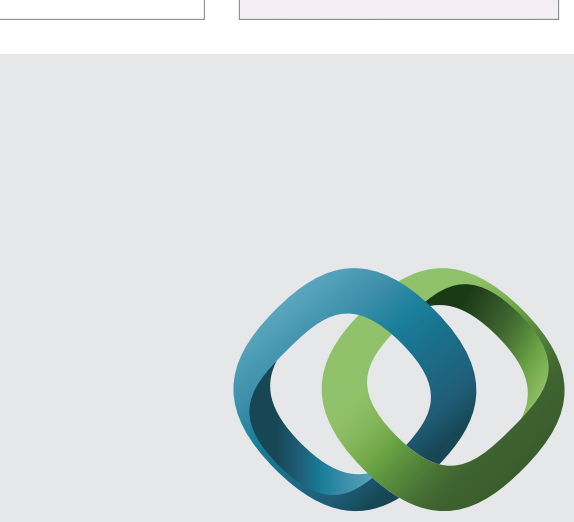

\section{Hindawi}

Submit your manuscripts at

http://www.hindawi.com
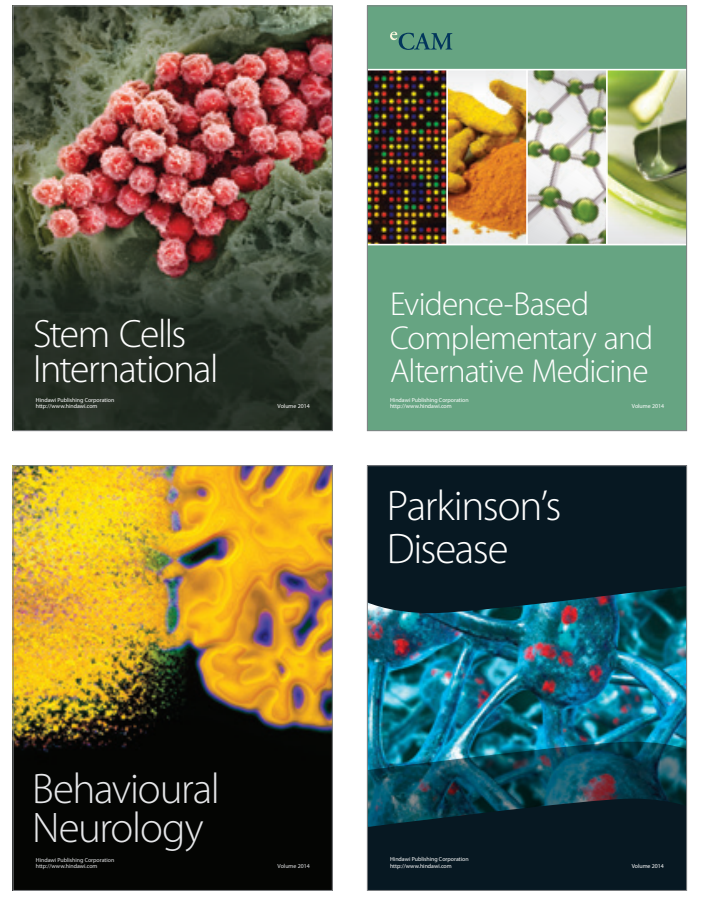
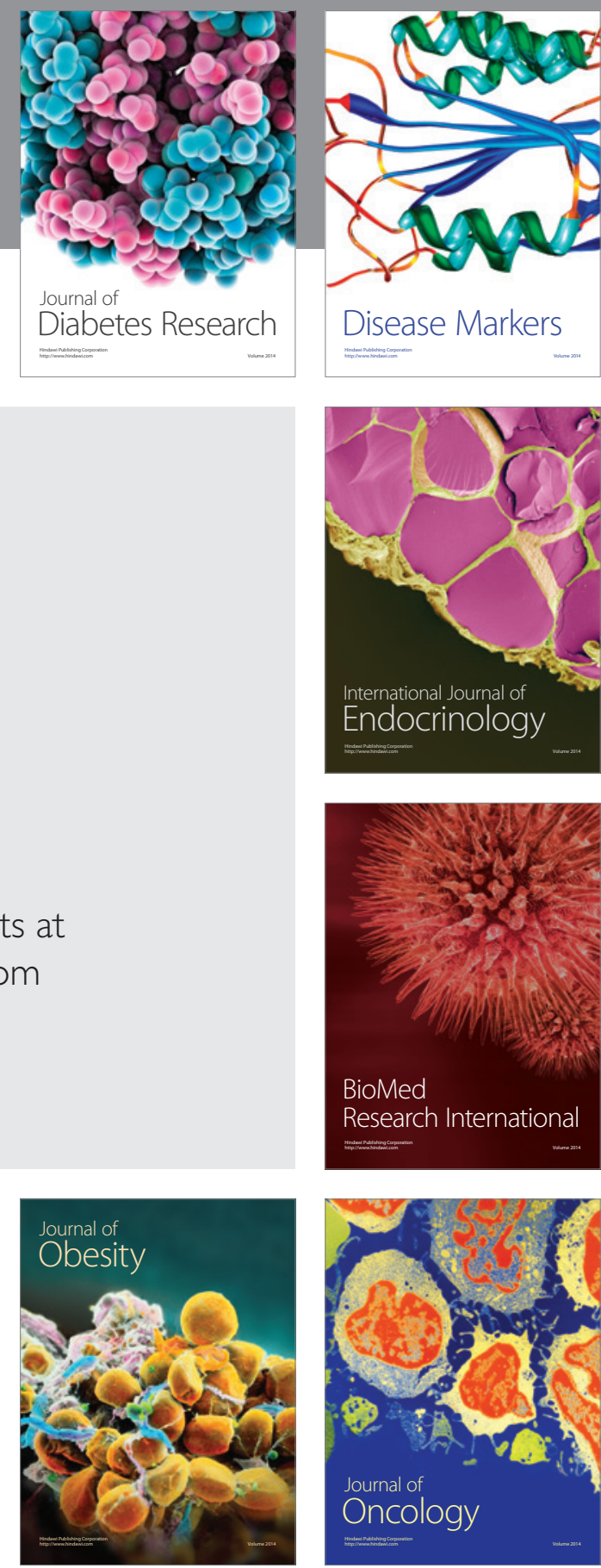

Disease Markers
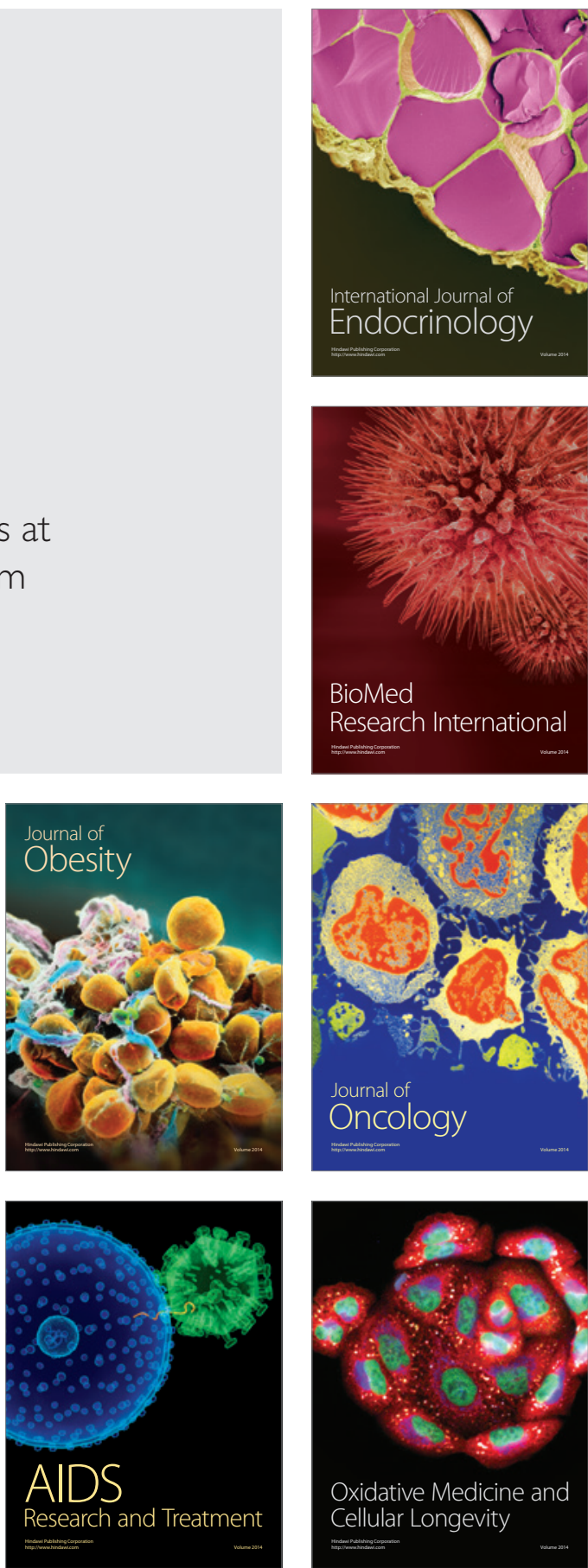